\title{
Article \\ Characterization of the Ghd8 Flowering Time Gene in a Mini-Core Collection of Miscanthus sinensis
}

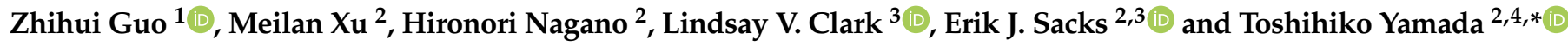 \\ 1 Graduate School of Environmental Science, Hokkaido University, Sapporo, Hokkaido 060-0810, Japan; \\ guozhihui-2008@hotmail.com \\ 2 Field Science Center for Northern Biosphere, Hokkaido University, Sapporo, Hokkaido 060-0811, Japan; \\ xumeilan0506@gmail.com (M.X.); nagano2@fsc.hokudai.ac.jp (H.N.); esacks@illinois.edu (E.J.S.) \\ 3 Department of Crop Sciences, University of Illinois, Urbana-Champaign, Urbana, IL 61801, USA; \\ lvclark@illinois.edu \\ 4 Global Center for the Research of Food, Land and Water Resources, Hokkaido University, Sapporo, \\ Hokkaido 060-8589, Japan \\ * Correspondence: yamada@fsc.hokudai.ac.jp; Tel.: +81-11-706-3644
}

Citation: Guo, Z.; Xu, M.; Nagano, H.; Clark, L.V.; Sacks, E.J.; Yamada, T. Characterization of the Ghd8 Flowering Time Gene in a Mini-Core Collection of Miscanthus sinensis. Genes 2021, 12, 288. https://doi.org/10.3390/ genes 12020288

Academic Editor: Paloma Mas

Received: 7 January 2021

Accepted: 15 February 2021

Published: 19 February 2021

Publisher's Note: MDPI stays neutral with regard to jurisdictional claims in published maps and institutional affiliations.

Copyright: (c) 2021 by the authors. Licensee MDPI, Basel, Switzerland. This article is an open access article distributed under the terms and conditions of the Creative Commons Attribution (CC BY) license (https:// creativecommons.org/licenses/by/ $4.0 /)$.

\begin{abstract}
The optimal flowering time for bioenergy crop Miscanthus is essential for environmental adaptability and biomass accumulation. However, little is known about how genes controlling flowering in other grasses contribute to flowering regulation in Miscanthus. Here, we report on the sequence characterization and gene expression of Miscanthus sinensis Ghd8, a transcription factor encoding a HAP3/NF-YB DNA-binding domain, which has been identified as a major quantitative trait locus in rice, with pleiotropic effects on grain yield, heading date and plant height. In M. sinensis, we identified two homoeologous loci, MsiGhd8A located on chromosome 13 and MsiGhd8B on chromosome 7, with one on each of this paleo-allotetraploid species' subgenomes. A total of 46 alleles and 28 predicted protein sequence types were identified in 12 wild-collected accessions. Several variants of MsiGhd8 showed a geographic and latitudinal distribution. Quantitative real-time PCR revealed that MsiGhd8 expressed under both long days and short days, and MsiGhd8B showed a significantly higher expression than $M s i G h d 8 A$. The comparison between flowering time and gene expression indicated that $M s i G h d 8 B$ affected flowering time in response to day length for some accessions. This study provides insight into the conserved function of Ghd8 in the Poaceae, and is an important initial step in elucidating the flowering regulatory network of Miscanthus.
\end{abstract}

Keywords: Miscanthus sinensis; Ghd8; gene expression; flowering time; sequence diversity; geographic distribution

\section{Introduction}

The genus Miscanthus is a rhizomatous, self-incompatible, C4 perennial grass that has a natural distribution from the tropics to $\sim 50^{\circ} \mathrm{N}$ in East Asia and Oceania [1], including Miscanthus sinensis, Miscanthus floridulus and Miscanthus sacchariflorus, and is closely related to sugarcane (Saccharum officinarum) and sorghum (Sorghum bicolor). Owing to its environmental adaptability, Miscanthus is used as forage for livestock feed, as an ornamental for landscapes, and as a bioenergy crop that provides high yields with low nutrient requirements [2,3]. For Miscanthus production, optimization of flowering time is essential to obtain high biomass yield under different environments [4,5], and may also impact biomass quality [6]. Controlling flowering also assists intra- and interspecific hybridizations between Miscanthus and Saccharum to facilitate the introgression of genes for disease resistance and abiotic stress tolerance from Miscanthus to sugarcane [7]. Additionally, to develop seed-based hybrid cultivars of Miscanthus, uniform flowering of the parental genotypes will be needed, and this has the potential to reduce the cost of establishment and accelerate domestication relative to the current standard approach of vegetatively 
propagating rhizomes of Miscanthus $\times$ giganteus, which is a hybrid between $M$. sacchariflorus and $M$. sinensis, and has recently attracted considerable attention as a feedstock crop for bioenergy [8,9].

Miscanthus has a long life span, exceeding 15 years, and it typically flowers annually [10], indicating that it has a complex mechanism for renewed vegetative growth after flower initiation. Initially, M. sinensis was described as a day neutral plant by Deuter [11], whereas Jensen et al. [8] demonstrated that flowering regulation in $M$. sinensis was complex, operated by thermal time/degree days but also a photoperiod sensitivity mechanism. In their latest study, Dong et al. [7] reported that $M$. sinensis was a facultative short-day (SD) plant, and photoperiod strongly affected Miscanthus flowering. Thus, it would be desirable to study the photoperiod regulation of flowering time in $M$. sinensis. The major regulatory genes for photoperiod control of flowering have been evolutionarily conserved in flowering plants but their specific effects can vary greatly among genera and species [12]. To date, the photoperiod regulation of flowering has been extensively investigated in the SD plant rice (Oryza sativa), and two independent genetic pathways have been identified [12]. One is the rice OsGI-Hd1-Hd3a pathway, which has been conserved in the SD plant sorghum [13], and is orthologous with the GI-CO-FT pathway in the long-day (LD) plant Arabidopsis [12]. In rice, GIGANTEA (GI) upregulates HEADING DATE 1 (Hd1), the ortholog of CONSTANS (CO), which regulates the expression of HEADING DATE $3 a$ ( $H d 3 a)$ to promote flowering in SD and delay flowering in LD [14-16]. Another flowering time pathway is Ghd7-Ehd1-Hd3a, which has been found in rice, sorghum and maize (Zea mays) but is absent from Arabidopsis thaliana [12,17-20]. GRAIN NUMBER, PLANT HEIGHT AND HEADING DATE 7 (Ghd7) is a grass-specific regulator of flowering and related traits. In rice, Ghd7 represses flowering under LD by down-regulating EARLY HEADING DATE 1 (Ehd1) and Hd3a [19]. In SD, Ehd1 activates $H d 3 a$ expression and induces floral transition [17,21]. Ehd1 is regulated by many genes, including Hd1, GI, Ghd7, PSEUDORESPONSE REGULATOR PROTEIN 37 (PRR37), and GRAIN NUMBER, PLANT HEIGHT AND HEADING DATE 8 (Ghd8) [19,22-25]. In sorghum, there is a similar but not identical flowering time pathway. Sorghum CENTRORADIALIS 15 (SbCN15), the sorghum ortholog of rice Hd3a (FLOWERING LOCUS T, FT), may modify flowering time in a photoperiod-insensitive manner $[18,26,27]$. SbCO acts as an activator of flowering in SD by inducing the expression of SbEhd1, SbCN8 and SbCN12 (FT-like genes), whereas in LD, SbCO activity is inhibited by SbPRR37 [13]. SbPRR37 [Maturity1(Ma1)] and SbGhd7 (Ma6), which are promoted by sorghum PHYTOCHROME B $(S b P h y B)$, inhibit flowering by decreasing the expression of SbEhd1, SbCN8 and SbCN12 under LD [18,26,27]. Ma2 delayed flowering in LD by selectively enhancing the expression of SbPRR37 and SbCO [28].

To date, information on the genetics of flowering regulation in Miscanthus is in its infancy $[4,7,8]$. Genetic linkage maps revealed fourteen flowering time quantitative trait loci (QTLs) in Miscanthus [29-31]. Dong et al. [29] found one Miscanthus flowering QTL on LG02 that corresponded to sorghum maturity gene Ma3 (PhyB) [26] and another located on LG01 that corresponded to the ASYMMETRIC LEAVES-like1 gene, which controls proximaldistal patterning in Arabidopsis petals [32]. Gifford et al. [30] found a Miscanthus QTL that corresponded to sorghum maturity gene Ma5 (PHYTOCHROME C, PhyC). Jensen et al. [31] reported eleven flowering QTLs on LG04 in $M$. sinensis, three of which were robust QTLs related to the age-dependent flowering pathway (SQUAMOSA PROMOTER BINDING PROTEIN-LIKE and MADS-box SEPELLATA2) and the gibberellin pathway (gibberellinresponsive bHLH137). However, the functions of these candidate flowering time genes in the Miscanthus QTLs have yet to be verified, and allelic sequence variation for these genes has yet to be described. At present, $\mathrm{Hd1} / \mathrm{CO}$ is the only candidate flowering time gene that has been screened in Miscanthus for sequence diversity and its geographic distribution, with large differences found among accessions from the Asian mainland relative to those from the Japanese archipelago [33].

Recently, Ghd8 (DTH8/LHD1/Hd5/LH8) has been found to be a key regulator of the Ghd7-Ehd1-Hd3a pathway in rice [34]. Ghd8 was initially identified as HAP3b in Arabidopsis, 
which can promote flowering in Arabidopsis by enhancing the expression of key flowering time genes, such as FT and SUPPRESSOR OF OVEREXPRESSION OF CONSTANS1 (SOC1), under LD [35]. In rice, Ghd8 has a dual function to inhibit flowering under LD and promote flowering under SD by regulating Ghd7, Ehd1, RICE FLOWERING LOCUS T 1 (RFT1) and $H d 3 a[22,23]$. In particular, Ghd8 encodes a protein transcription factor, heme activator protein 3 (HAP3) / nuclear factor-YB (NF-YB), that in rice binds to CCAAT motif in the promoter region of Ghd7, as part of a complex with HD1 and OsHAP5b [34]. In rice, a $19 \mathrm{bp}$ deletion in Ghd8 causes a loss-of-function that confers early flowering and thus adaptation to high latitudes; this allele is widely distributed among cultivars from Northern China and Japan [36,37], and has been selected and used widely for breeding early heading varieties in Hokkaido [37]. Therefore, Ghd8 plays a key role in the domestication and adaptation of rice in Hokkaido. It is worthwhile to investigate if a similar process occurred in Miscanthus during its migration northward after the last glacial maximum. Ehd1 in rice is induced by blue light in the morning, and Ghd7 suppression of Ehd1 is induced by red light in the morning under LD, thereby suppressing flowering, whereas under SD, the peak of Ghd7 expression shifts to night, and this misaligned timing allows Ehd1 to induce Hd3a and promote flowering [12]. Genomic synteny and collinearity are common features in the Poaceae [38,39], and have also been confirmed among rice, sorghum, switchgrass and M. sinensis genomes [29,31,40-43]. Previous studies have identified genes/QTLs under parallel evolution across grass species $[31,33,44-48]$. To date, there have been no reports of Ghd8 in C4 bioenergy crops such as sorghum, switchgrass and Miscanthus. Thus, a key question this study seeks to answer is the following: does $M$. sinensis have a functional Ghd8 that contributes to the regulation of flowering time? Moreover, we expect that if Ghd8 regulates flowering in M. sinensis, the gene's expression in the day will follow a pattern of differential flowering times under LD relative to SD. In this study, we cloned the ortholog of OsGhd8 in a mini-core collection of $M$. sinensis with the aim to 1) characterize allelic and deduced amino acid sequence diversity and geographic distribution, and 2) determine expression patterns in response to photoperiod and relate these to previously obtained data on days to first flower under LD and SD.

\section{Materials and Methods}

\subsection{Plant Materials and Growth Conditions}

Twelve Miscanthus accessions (clones maintained by vegetative propagation) were studied for gene sequence variation and expression over time in response to two photoperiod treatments ( $15 \mathrm{~h}, \mathrm{LD} ; 12.5 \mathrm{~h}, \mathrm{SD}$ ) (Table 1). The twelve accessions included eleven M. sinensis from known locations in China and Japan, representing latitudes ranging from $18^{\circ} \mathrm{N}$ to $45^{\circ} \mathrm{N}$, and one $\mathrm{M}$. floridulus from $20.9^{\circ} \mathrm{S}$ in New Caledonia (we consider $M$. floridulus conspecific with $M$. sinensis $[49,50]$ and hereafter refer to the entire panel as M. sinensis). The M. sinensis accessions represent six genetic groups that were previously identified by Clark et al. [49,50]. Dong et al. [7] previously evaluated the same twelve accessions for days to first flowering under day lengths of $15,12.5$ and $10 \mathrm{~h}$ in controlled environment chambers, and observed strong flowering time responses that varied by latitude of origin. In the current study, six pots of each accession were established by planting rhizomes in $2 \mathrm{~L}$ plastic pots containing soilless medium consisting of compost, vermiculite, calcined clay and peat moss (Forex Mori Sangyo Co., Ltd., Hokkaido, Japan) and growing these in a greenhouse at Hokkaido University in Sapporo, Japan $\left(43.1^{\circ} \mathrm{N}, 141.3^{\circ} \mathrm{E}\right)$, with natural photoperiod. 


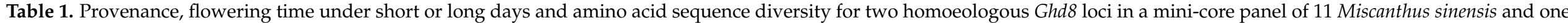
Miscanthus floridulus accessions.

\begin{tabular}{|c|c|c|c|c|c|c|c|c|c|c|c|}
\hline \multirow{3}{*}{$\begin{array}{l}\text { Genotypes } \\
\text { M. sinensis "Teshio" }\end{array}$} & \multirow{3}{*}{$\begin{array}{l}\text { Ploidy } \\
2 x\end{array}$} & \multirow{3}{*}{$\begin{array}{l}\text { Lat } \\
44.9\end{array}$} & \multirow{3}{*}{$\begin{array}{r}\text { Long } \\
141.9\end{array}$} & \multirow{3}{*}{$\begin{array}{l}\text { Genetic Group † } \\
\text { Northern Japan }\end{array}$} & \multirow{3}{*}{$\begin{array}{l}\text { Genetic Group Color Code }+ \\
\text { Blue }\end{array}$} & \multicolumn{2}{|c|}{ Days to First Flowering $\ddagger$} & \multicolumn{4}{|c|}{ Variant Types Classified by Predicted Protein in Ghd8 Homoeologs } \\
\hline & & & & & & \multirow[t]{2}{*}{$12.5 \mathrm{~h}$} & \multirow[t]{2}{*}{$15 \mathrm{~h}$} & \multicolumn{2}{|c|}{ MsiGhd8A } & \multicolumn{2}{|c|}{ MsiGhd8B } \\
\hline & & & & & & & & A1 & A2 & B1 & B2 \\
\hline M. sinensis "Sugadaira" & $2 x$ & 36.0 & 138.1 & Southern Japan & Yellow & & 96 & A3 & A4 & B3 & B4 \\
\hline M. sinensis "Miyazaki" & $2 x$ & 31.8 & 131.4 & Southern Japan & Yellow & 61 & 167 & A5 & A6 & B5 & B6 \\
\hline M. sinensis "PMS-436" & $2 x$ & 41.3 & 123.7 & Korea/North China & Red & & 115 & A3 & A7 & B7 & B8 \\
\hline M. sinensis "PMS-164" & $2 x$ & 37.3 & 114.3 & Yangtze-Qinling & Green & & 130 & A8 & A8 & B8 & B8 \\
\hline M. sinensis "PMS-306" & $2 x$ & 29.9 & 118.8 & Yangtze-Qinling & Green & 84 & 173 & A8 & A9 & B8 & B8 \\
\hline M. sinensis "PMS-226" & $2 x$ & 26.6 & 106.8 & Sichuan Basin & Orange & 76 & 189 & A1 & A7 & B9 & $\mathrm{B} 10$ \\
\hline M. sinensis "Onna-1a" & $2 x$ & 26.5 & 126.8 & SE China plus tropical & Purple & & 274 & $\mathrm{~A} 10$ & & B11 & B12 \\
\hline M. sinensis "PMS-359" & $2 x$ & 22.9 & 112.3 & SE China plus tropical & Purple & 81 & 179 & A11 & A7 & B8 & B13 \\
\hline M. sinensis "PMS-375" & $2 x$ & 19.6 & 110.3 & SE China plus tropical & Purple & 142 & & A11 & & B9 & B9 \\
\hline M. sinensis "PMS-382" & $2 x$ & 18.9 & 109.5 & SE China plus tropical & Purple & 184 & & A11 & $\mathrm{A} 12$ & B1 & B1 \\
\hline M. floridulus “US56-0022-03” & $2 x$ & -20.9 & 165.3 & SE China plus tropical & Purple & 114 & & A11 & A13 & B14 & B15 \\
\hline
\end{tabular}

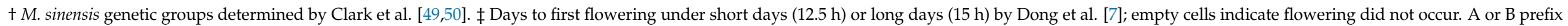

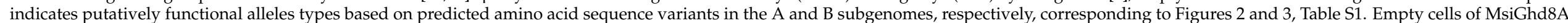
indicated that only one allele type was detected in Onna-1a and PMS-375, and therefore, these two accessions were homozygous at MsiGhd8A. 
After $40 \mathrm{~d}$ of establishment in the greenhouse, the Miscanthus plants were cut to $5 \mathrm{~cm}$ above the soil surface and moved into growth chambers (BioTRON LH-350S, NK Systems, Nippon Medical \& Chemical Instruments Co., Ltd., Osaka, Japan) under constant long days $(15 \mathrm{~h})$. Pots were rotated randomly inside and between the chambers on a daily basis to minimize between-chamber and within-chamber environmental effects. The growth chambers provided $400 \pm 50 \mu \mathrm{mol} \mathrm{m}{ }^{-2} \mathrm{~s}^{-1}$ of photosynthetically active radiation with fluorescent lamps (Hitachi FLR40S-EX-N/M/36-A, Hitachi, Ltd., Tokyo, Japan), as measured with a quantum sensor (MIJ-14PARII, Environmental Measurement, Fukuoka, Japan). After $30 \mathrm{~d}$ of establishment in the chambers, the plants were subjected to one of two day-length treatments: LD ( $15 \mathrm{~h}$ light $/ 9 \mathrm{~h}$ dark) and SD ( $12.5 \mathrm{~h}$ light/11.5 h dark), with three pots per accession given LD and three given SD. The temperature in the chambers was a constant $23{ }^{\circ} \mathrm{C}$ for the duration of the experiment. At planting and again at the start of each experiment, $15 \mathrm{~g}$ of 12-9-12 compound fertilizer (Kumiai Grassland No. 8; Hokkaido Fertilizer Co., Ltd., Japan) was added to each pot. Irrigation was provided to each pot each day. At day 38, one week after commencement of the LD or SD treatment, the three topmost leaves from each of the three pots per accession within each treatment were harvested and pooled at Zeitgeber times (ZT) of 3, 9, 15 and $21 \mathrm{~h}$ for one 24 hour light-dark cycle.

\subsection{Genomic DNA Extraction and Isolation of Ghd8 in Miscanthus}

Genomic DNA was isolated from young, healthy leaves by the modified cetyltrimethylammonium bromide (CTAB) [51] protocol using the DNeasy Plant Mini Kit (Qiagen, Tokyo, Japan) according to the manufacturer's instructions. Gene-specific primers (Forward primer 1: 5'-GAAAGGCGATTAAGAGGAGAAT-3'; Forward primer 2: 5'-CACCATAAGCTAGCT GACTAGCT-3'; Reverse primer 1: 5'-GCAAGTATCGTTTGTCGTCGTCTT-3') for Ghd8 were designed by aligning multiple sequences retrieved from the Miscanthus sinensis v7.1 genome [41] and its close relative sorghum using the Sorghum bicolor v3.1 genome from Phytozome v.13 (https:/ / phytozome-next.jgi.doe.gov (accessed on 15 September 2019)). Amplification of $G h d 8$ was accomplished by polymerase chain reactions (PCRs) containing $30 \mathrm{ng}$ of total genomic DNA as a template and LA Taq polymerase (TaKaRa Bio, Shiga, Japan). Amplification conditions were $1 \mathrm{~min}$ at $95^{\circ} \mathrm{C}$, followed by 30 cycles of $30 \mathrm{~s}$ at $95^{\circ} \mathrm{C}, 30 \mathrm{~s}$ at suitable primer temperature and $1 \mathrm{~m} 30 \mathrm{~s}$ at $72{ }^{\circ} \mathrm{C}$. PCR products were separated on $0.8 \%$ agarose gels by electrophoresis. Amplified bands of desired molecular weight were eluted from the agarose gel with the NucleoSpin ${ }^{\circledR}$ Gel and PCR Clean-up kit (Macherey-Nager GmbH \& Co. KG, Düren, Germany) and cloned into a pGEM-T Easy vector (Promega, Madison, WI, USA) using the TA-Blunt Ligation Kit (Nippon Gene Co., Ltd., Toyama, Japan) following the manufacturer's instructions. Positively transformed colonies were selected on blue-white selection on ampicillin/IPTG/X-Gal LB plates, and plasmids were purified using a High Pure Plasmid Isolation Kit (Roche, Sigma-Aldrich, Tokyo, Japan). About 20 plasmid clones of each genotype were sequenced in both directions with a BigDye Terminator v3.1 Cycle Sequencing Kit (Applied Biosystems, Foster City, CA, USA) via an ABI PRISM 3130 Genetic Analyzer (Life Technologies, Carlsbad, CA, USA) according to the manufacturer's instructions. To identify true alleles and to limit the potential for misidentifying point mutations and indels resulting from PCR and sequencing errors as true alleles, we set a quality-control threshold of at least three colonies with the identical sequence for inclusion in further analysis and reporting.

\subsection{RNA Isolation and Quantitative Reverse Transcription-PCR Analysis}

Leaves were sampled from fully expanded healthy leaves at ZT 3, 9, 15 and $21 \mathrm{~h}$ in the growth chamber. All samples were immediately frozen in liquid nitrogen and stored at $-80^{\circ} \mathrm{C}$ until analysis. Total RNA was isolated from frozen leaves with a Favorgen ${ }^{\circledR}$ Plant Total RNA Extraction Mini Kit (Favorgen Biotech Corp., Taiwan) and treated with DNase I (TaKaRa Bio, Shiga, Japan) to remove contaminating genomic DNA. cDNA was synthesized from purified RNA using an oligo (dT) 20 primer and random hexamer primers with Invitrogen ${ }^{\mathrm{TM}} \mathrm{M}-\mathrm{MLV}$ Reverse Transcriptase (Invitrogen, Carlsbad, CA, USA) according to 
Dwiyanti et al. [52]. The transcript levels for candidate genes were determined by quantitative real-time PCR (qRT-PCR). The PCR reactions $(20 \mu \mathrm{L})$ contained $4.6 \mu \mathrm{L}$ of the cDNA synthesis reaction mixture diluted to $1 / 15$ th of its original volume, $5 \mu \mathrm{L}$ of $1.2 \mu \mathrm{M}$ primer premix, $0.4 \mu \mathrm{L}$ ROX Reference Dye $(50 \times)$ and $10 \mu \mathrm{L}$ of TB Green ${ }^{\circledR}$ Premix Ex Taq ${ }^{\mathrm{TM}}$ II $(\mathrm{Tli}$ RNaseH Plus) (TaKaRa Bio, Shiga, Japan). Expression levels were determined on a StepOnePlus $^{\mathrm{TM}}$ Real-Time PCR System (Applied Biosystems, Foster City, CA, USA) with cycling conditions of $95^{\circ} \mathrm{C}$ for $5 \mathrm{~min}$, followed by 40 cycles of $95^{\circ} \mathrm{C}$ for $10 \mathrm{~s}, 60^{\circ} \mathrm{C}$ for $20 \mathrm{~s}$ and $72{ }^{\circ} \mathrm{C}$ for $30 \mathrm{~s}$. Values were normalized to ACTIN (Misin17G008500) as an internal control. A reaction mixture without reverse transcriptase was also used as a control to confirm the absence of genomic DNA contamination. Amplification of a single DNA fragment was confirmed by melting-curve analysis of quantitative PCR and gel electrophoresis of the PCR products. Relative changes in gene expression were estimated following the $2^{-\Delta \Delta C t}$ method [53]. Averages and standard errors of relative expression levels were calculated for three independently synthesized cDNAs. The forward primer used for ACTIN (Misin17G008500) gene expression was 5'-AGGGCTGTTTTCCCTAGCATCGT-3', and the reverse primer was 5'-GGGTACTTGAGCGTGAGAATACCTC-3'. Primers were designed for MsiGhd8 based on the putative functional alleles. The forward primer used for MsiGhd8A (Misin13G040800) gene expression was 5'-CTCAACCGCTACCGCGAGGTC-3', and the reverse primer was 5'TCATCCGCCGCGCCATCT-3'. The forward primer used for MsiGhd8B (Misin07G127500) gene expression was 5'-ACGTCGGGCTCATGATGGGAGCA-3', and the reverse primer was 5'-ATACGACTTCCGTGCTGCCGT-3'.

\subsection{Data Analysis}

The nucleotide sequences were assembled with ATGC v.6 software (GENETYX Co., Tokyo, Japan). O. sativa, S. bioclor, M. sinenesis genome sequences (Phytozome v.13, $100 \mathrm{~kb}$ ) spanning Ghd8 gene were used for microsynteny / collinearity analysis, which was determined and visualized by Genome Evolution Analysis (GEvo) (http: / genomevolution.org / CoGe/GEvo.pl (accessed on 2 January 2021)) and the high-resolution sequence analysis tool from the Accelerating Comparative Genomics (CoGe) toolkit (http: / genomevolution.org / CoGe/ (accessed on 2 January 2021)). Multiple alignments of nucleotide and amino acid sequences were implemented in MEGA X [54-56], using ClustalW [57] with default settings. Phylogenetic trees were generated in MEGA X [54,55] using the Neighbor-Joining (NJ) method [58] with the substitutional model of Kimura 2-parameter [59]. The corresponding sequences of rice and sorghum were used as an out-group. Support for each node was tested with 1000 bootstrap repetitions [60]. The trees were edited and visualized in FigTree ver.1.4.4 (http:/ / tree.bio.ed.ac.uk/software/figtree/ (accessed on 5 September 2020)). Relative changes in mean \pm standard error of the mean (SE) gene expression were analyzed in Microsoft Excel (Microsoft Office 2016, Microsoft Inc., Seattle, WA, USA) and then exported to GraphPad Prism 9 software (GraphPad Software, San Diego, CA, USA) for visualization. Statistical tests for differences among means were conducted by a Student's $t$-test or analyses of variances (ANOVAs) using GraphPad Prism 9 software (GraphPad Software, San Diego, CA, USA). The DNA sequences obtained are available from DDBJ (http: / / www.ddbj.nig.ac.jp/index-e.html (accessed on 21 December 2020)) with the accession numbers LC598392 to LC598437.

\section{Results}

\subsection{Characterization of $M$. sinensis Ghd8}

In M. sinensis, two homoeologous Ghd8 loci, MsiGhd8A located on chromosome 13 (Chr.13) and MsiGhd8B on chromosome 7 (Chr.07), were identified, with one on each of this paleo-allotetraploid species' subgenomes (Figure 1). A total of $46 \mathrm{MsiGhd8}$ alleles were identified from the 12 wild-collected M. sinensis accessions (Figure 2 and Table S1). Sequence alignment indicated that the ORF lengths of $M$. sinensis Ghd8 ranged from 813 to 831 nucleotides, and contained one exon that coded for 270 to 276 amino acid residues (Figure 1). Multiple sequence blasting in Phytozome v13 (https:/ / phytozome-next.jgi.doe. gov(accessed on 20 March 2020)) revealed that the nucleotide sequences of $M$. sinensis Ghd8 
were highly similar to those in other plant species, such as S. bicolor (Sobic.007G059500, 88.6-92.3\%), O. sativa (LOC_Os08g07740, 72.2-73.3\%), Z. mays (Zm0001d049485, 82.7-86.3\%) and A. thaliana (AT5G47640, 32.0-32.9\%). A microsynteny assessment of genomic regions adjacent to Ghd 8 in rice, sorghum and $M$. sinensis identified four colinear genes, including Ghd8, aligned with the same relative genomic order in a $100 \mathrm{kbp}$ region, which was consistent with the identification of LOC_Os08g07740 as an ortholog of rice Ghd8 [22] (Figure S1 and Table S2). Therefore, based on sequence similarity and gene collinearity, two homoeologous Ghd8 loci in M. sinensis were designated as orthologs of Ghd8 in rice and sorghum, and probable orthologs of $H A P 3 b$ in A. thaliana. Neighbor-Joining (NJ) phylogenetic trees revealed a robust separation of clades representing MsiGhd8A (22 alleles) and MsiGhd8B (24 alleles) (Figure 2). The phylogenetic trees indicated that the sorghum Ghd8 was more similar to MsiGhd8B than MsiGhd8A. Two accessions (Onna-1a and PMS$375,16.7 \%$ ) were homozygous at the MsiGhd8A locus, and all accessions were heterozygous at the MsiGhd8B locus (Table 1). Pairwise DNA sequence comparisons showed that the similarity of MsiGhd8A open reading frame (ORFs) ranged from $98.7 \%$ (Teshio -Func2 vs. PMS-226 -Func2, Teshio -Func2 vs. PMS-382 -Func2, Teshio -Func2 vs. US56-0022-03 -Func2) to $100 \%$ (Sugadaira -Func1 vs. PMS-436 -Func1, PMS-164 -Func1 vs. PMS-306 -Func1, PMS375 -Func1 vs. PMS-382 -Func1) (Table S1). Similarly, the nucleotide sequence similarity of MsiGhd8B ORFs varied from 97.9\% (Sugadaira -Func4 vs. US56-0022- 03-Func4) to 100\% (PMS-164 -Func3 vs. PMS-306 -Func3, PMS-164 -Func4 vs. PMS-436 -Func4, PMS-226 -Func3 vs. PMS-375 -Func3) (Table S1).

(a)

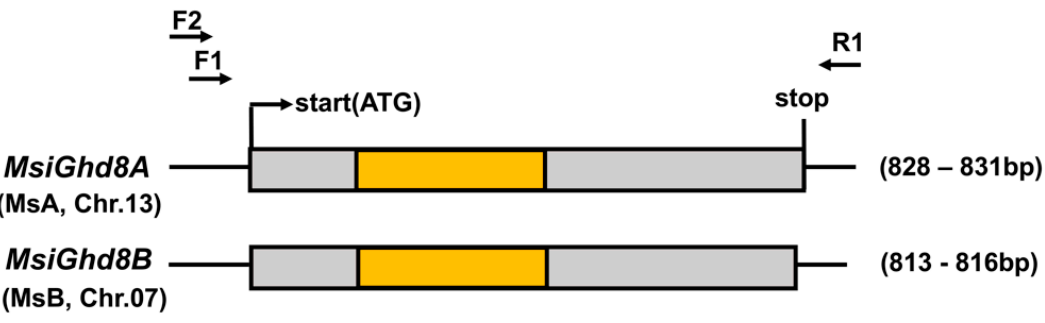

MsiGhd8A(Chr.13)
MsiGhd8B(Chr.07)
Sobic.007G059500
LOC_Os08g07740
Zm00001d049485
AT5G47640
MsiGhd8A(Chr.13)
MsiGhd8B(Chr.07)
Sobic.007G059500
LOC_Os08g07740
Zm00001d049485
AT5G47640

(b)

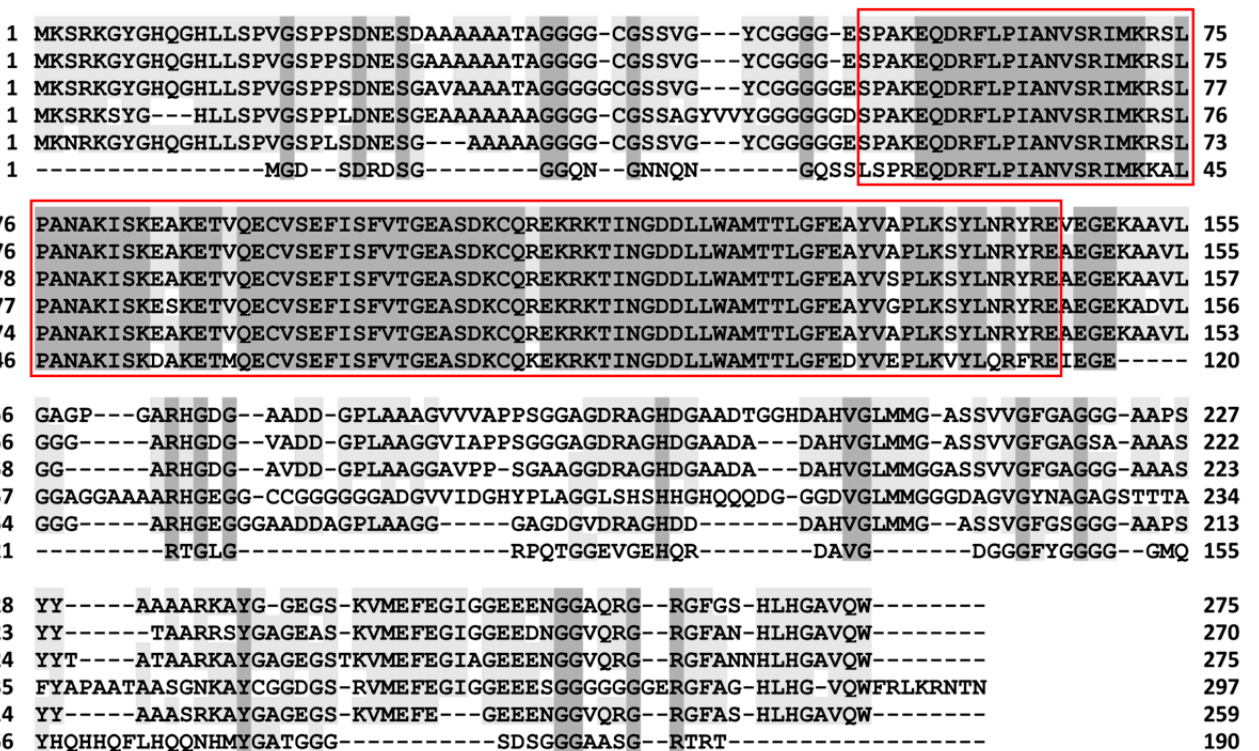

1 MKSRKGYGHQGHLLSPVGSPPSDNESDAAAAAATAGGGG-CGSSVG---YCGGGG-ESPAKEQDRFLPIANVSRIMKRSL 75 1 MKSRKGYGHQGHLLSPVGSPPSDNESGAAAAAATAGGGG-CGSSVG---YCGGGG-ESPAKEQDRFLPIANVSRIMIRSL 75 1 MKSRKGYGHQGHLLSPVGSPPSDNESGAVAAAATAGGGGCGSSVG---YCGGGGGESPAKEQDRFLPIANVSRIMKRSL 77 1 MKSRKSYG---HLLSPVGSPPLDNESGEAAAAAAAGGGG-CGSSAGYVVYGGGGGGDSPAKEQDRFLPIANVSRIMKRSL 76 1 MKNRKGYGHQGHLLSPVGSPLSDNESG---AAAAAGGGG-CGSSVG---YCGGGGGESPAKEQDRFLPIANVSRIMKRSL 73 PANAKISKEAKETVQECVSEFISFVTGEASDKCQREKRKTINGDDLLWAMTTLGFEAYVAPLKSYLNRYREVEGEKAAVL 155 76 PANAKISKEAKETVQECVSEFISFVTGEASDKCQREKRKTINGDDLLWAMTTLGFEAYVAPLKSYLNRYREAEGEKAAVL 155 78 PANAKISKEAKETVQECVSEFISFVTGEASDKCQREKRKTINGDDLLWAMTTLGFEAYVSPLKSYLNRYREAEGEKAAVL 157 PANAKI SKESKETVOECVSEFISFVTGEASDKCOREKRKTINGDDLLWAMTTLGFEAYVGPLKSYLNRYREAEGEKADVL 156 74 PANAKISKEAKETVOECVSEFISFVTGEASDKCOREKRKTINGDDLLWAMTTLGFEAYVAPLKSYLNRYREAEGEKAAVL 153 PANAKISKDAKETMQECVSEFISFVTGEASDKCQKEKRKTINGDDLLWAMTTLGFEDYVEPLKVYLQRFREIEGE----- 120

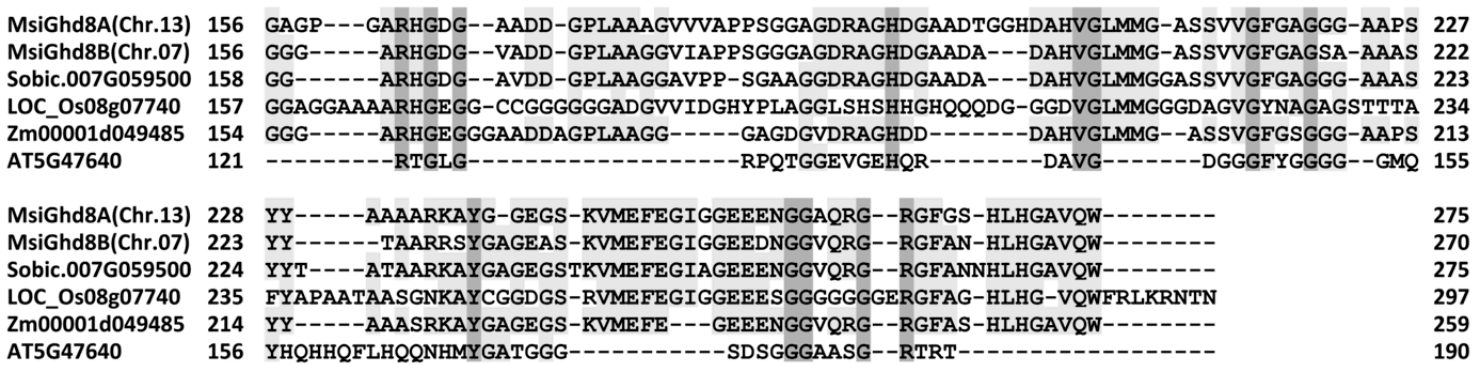

Figure 1. Gene structure and multiple alignment analysis of Miscanthus sinensis Ghd8 homoeologs and their comparison with orthologs from four other plant species. (a) Gene structure of MsiGhd8A and MsiGhd8B. F, forward primer; R, reverse primer; the primer pairs F1/R1 and/or F2/R1 were used to detect open reading frames (ORFs) for Ghd8. The start codon (ATG) and stop codon (TGA) are highlighted in black. The yellow box represents the HAP3/NF-YB domain. (b) Multiple amino acid sequence alignments for Ghd8 from M. sinensis (this study), Sorghum bicolor (Sobic.007g059500), Oryza sativa (LOC_Os08g07740), Zea mays (Zm0001d049485) and Arabidopsis thaliana (AT5G47640). The HAP3/NF-YB domain is boxed in red. The M. sinensis sequence used for alignment was from accession PMS-382. 


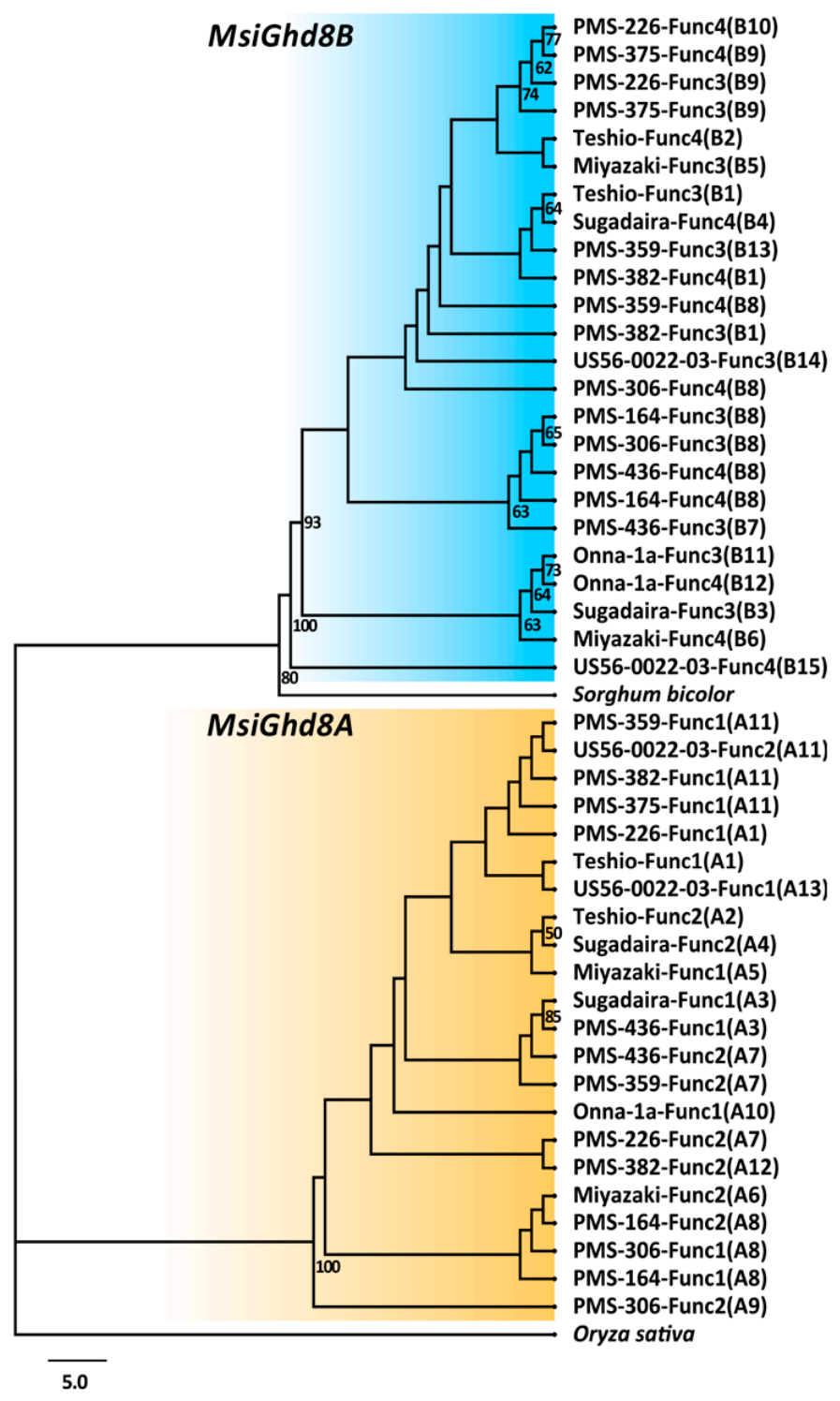

Figure 2. Phylogenetic tree inferred by neighbor-joining method for nucleotide sequences of 42 Ghd8 alleles from 11 accessions of Miscanthus sinensis and four alleles from one Miscanthus floridulus accession. Sorghum bicolor (Sobic.007g059500) and Oryza sativa (LOC_Os08g07740) were used as an out-group. The phylogenetic tree was divided into two clusters, which were classified as MsiGhd8A and MsiGhd8B, one for each of the two subgenomes. Bootstrap values for nodes supported in $>50 \%$ of 1000 bootstrap replicates are shown. Allele names with A or B prefix indicate putatively functional alleles types based on predicted amino acid sequence variants, which are named in parentheses and correspond to the names in Figure 3 and Figure S2, Table 1 and Table S1.

Comparison of the $46 \mathrm{MsiGhd8}$ alleles derived from the 12 wild-collected $\mathrm{M}$. sinensis accessions in this study with the alleles in the Miscanthus sinensis v7.1 genome [41] revealed 35 non-synonymous single nucleotide variants (nsSNVs), 36 synonymous single nucleotide variants (sSNVs) and two 3-bp insertions in ORFs, with some accessions having more than one SNV per allele (Table S1). Considering the fact that the nucleotide diversity cannot exactly represent the protein diversity owing to synonymous SNVs in ORFs, Ghd8 protein variant types were analyzed in the present study (Table 1 and Table S1, Figures 2 and 3). Accounting for nsSNVs, 13 predicted amino acid sequence types of MsiGhd8A and 15 of MsiGhd8B (28 total) were identified from the 12 M. sinensis accessions (Table 1 and Table S1, Figures 2 and 3). The amino acid sequence similarity of putatively functional MsiGhd8A and MsiGhd8B variants ranged from $92.1 \%$ to $94.2 \%$. Notably, the deduced amino acid 
sequence of Ghd8 in M. sinensis indicated that the gene products contain a HAP3/NF-YB DNA-binding domain located from position 53 to 146 (Figure 1b), which is critical for the transcription factor function of Ghd8 gene products. Though no putatively non-functional alleles were detected, four nsSNVs in the HAP3/NF-YB DNA-binding domain of MsiGhd8 (two in MsiGhd8A and two in MsiGhd8B) were observed in five accessions, with one nsSNV of MsiGhd8A found in each of two accessions (Sugadaira and PMS-436), one nsSNV of MsiGhd8A found in Teshio and one nsSNV of MsiGhd8B in PMS-226 and another nsSNV of MsiGhd8B found in US56-0022-03 (Table S1).
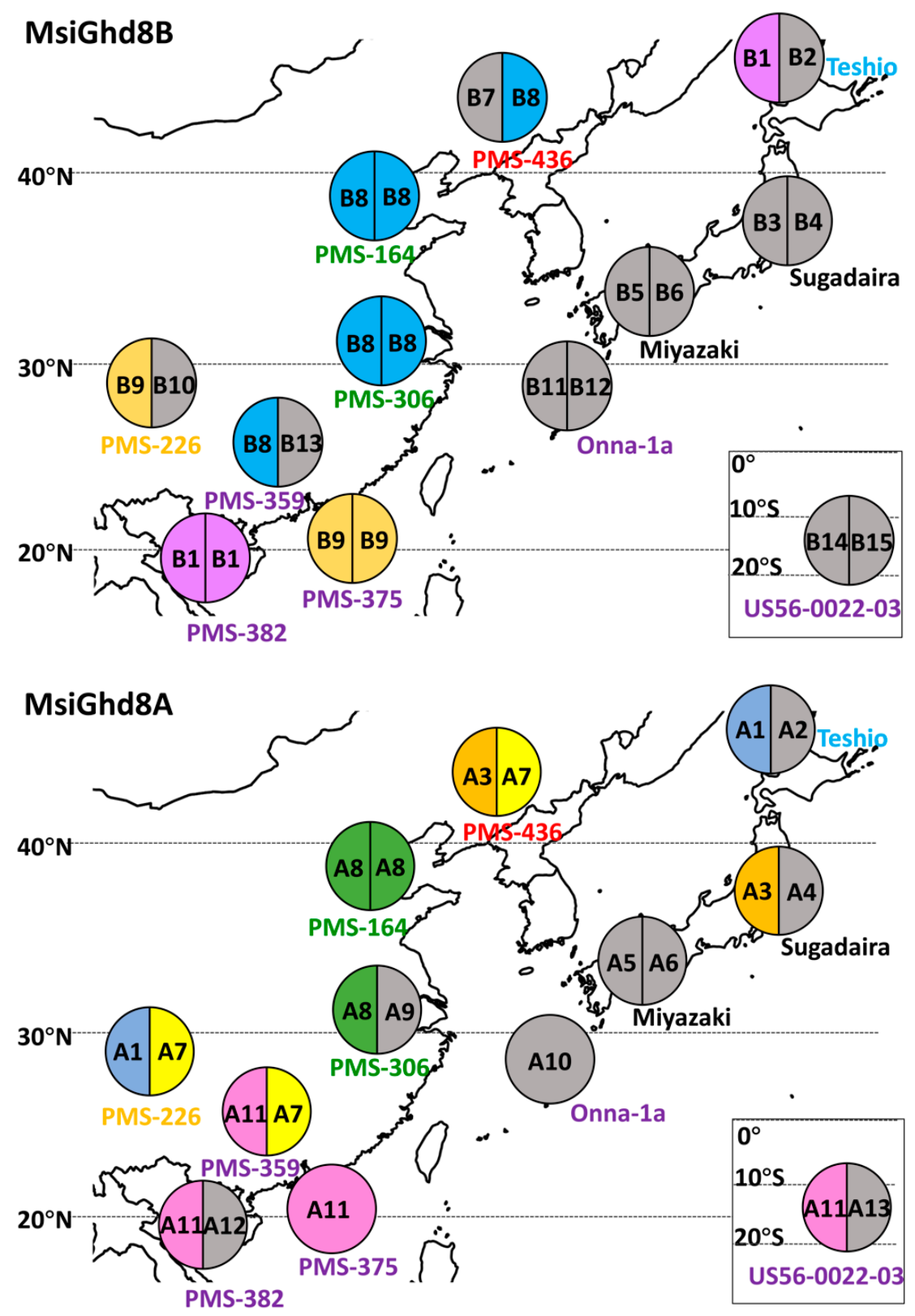

Figure 3. Geographical distribution of MsiGhd8A and MsiGhd8B predicted amino acid sequence variant types in Miscanthus sinensis. Pie charts with one to two sections represent the number of detected alleles. A or B prefix indicates putatively functional alleles types based on predicted amino acid sequence variants, corresponding to the names in Figure 2, Table 1 and Table S1. Different colors in pie charts represent different variant types that occurred in more than one accession; variant types that were observed only once have a gray background, corresponding to Table S1. Accessions' names were colored to represent $M$. sinensis genetic groups previously described by Clark et al. $[49,50]$; Sugadaira and Miyazaki were changed from yellow to black for making the map clear. 


\subsection{Geographical Distribution of Naturally Occurring MsiGhd8 Protein Variants}

Some of the MsiGhd8 protein variants were found over a broad geographic range, whereas others had restricted patterns of occurrence (Table 1, Figure 2, Figure 3 and Figure S1). In the A subgenome, variant A1 was the most broadly distributed, with occurrence in accessions that originated from the mid and highest latitudes in this study (PMS-226 from Sichuan basin and Teshio from northern Hokkaido Japan), but it was infrequently observed (16.7\% of accessions). In contrast, A7 was distributed widely and the second-most frequently observed variant ( $25 \%$ of accessions). A3 was limited to two accessions, one in Northern China and one in Central Japan; however, DNA sequence analysis indicated that A3 and A7 are closely related (Table S1) and thus represent a broadly distributed group in mainland Asia and Japan. A11 had a restricted distribution from New Caledonia to Guangdong China with a latitude ranging from $20.9^{\circ} \mathrm{S}$ to $22.9^{\circ} \mathrm{N}$ and was the most frequent variant (33.3\% of accessions) but was absent from mid and high latitudes in mainland Asia and Japan. However, phylogenetic analysis of the DNA sequence revealed that A11 and A1 protein variants were closely related and thus represented a widely distributed group from east to west and from north to south. A8 was limited to mid latitudes in mainland Asia. The other eight variants were each observed in only one accession. A2 and $\mathrm{A} 3$, which encode one additional amino acid resulting from the same 3-bp insertion in the nucleotide sequence, were limited to Northern Japan and China.

In the B subgenome, variant B1 was observed from Hainan to Hokkaido but infrequently (16.7\% of accessions). In mainland Asia, B8 was also broadly distributed from low to high latitude and frequent (25\% of accessions). B9 was observed in two accessions, one in Sichuan Basin and one in Southern China. The other twelve variants were each observed in only one accession. Phylogenetic analyses of DNA sequence indicated the following closely related protein variant groups: B7 and B8; B9 and B10; B1, B4 and B13; B3, B6, B11 and B12 (Figures 2 and 3).

\subsection{Expressions Patterns of M. sinensis Ghd8}

For each of the M. sinensis accessions, expression of Ghd8 (assessed as the ratio of Ghd8 / ACTIN mRNA transcript abundance) from the B subgenome was one to two orders of magnitude greater than for the A subgenome (Figures 4 and 5). Within each subgenome, large differences among the accessions for Ghd8 expression were observed (Figures 4 and 5). The two accessions with the highest morning-expression of MsiGhd8B under LD (Teshio and Onna-1a) also had the highest expression of MsiGhd8A (Figure 5). Interestingly, under LD, Onna-1a was the latest flowering of the accessions, but Teshio was the earliest flowering, and neither flowered under SD. Three patterns of diurnal MsiGhd8 expression were observed: day peak, night peak and no clear peak (Figure 5). The most common diurnal MsiGhd8 expression pattern observed was a day peak at ZT9 or ZT15 (Figure 5), which is later than the dawn peak that has been reported for rice, suggesting that optimal timing may differ between $M$. sinensis and rice. For the B subgenome, the LD/SD ratio of Ghd8 expression at ZT9, was $>1$ for three accessions, $<1$ for five accessions and $\sim 1$ for four accessions (Figure 5). Notably, two of the accessions with MsiGhd8B LD/SD ratios $\sim 1$ also had a relatively low expression, were from the tropics (PMS-382 and US56-0022-03) and were among the only three accessions in the panel that did not flower under LD (Figure 5, Table 1); the third accession (PMS-375) was similar, with a small but significantly lower expression under LD than SD at ZT9. In contrast to the B subgenome, the A subgenome LD/SD ratio of Ghd8 expression at ZT9 was $>1$ for only one accession (PMS-436) and $\sim 1$ for eleven accessions. 


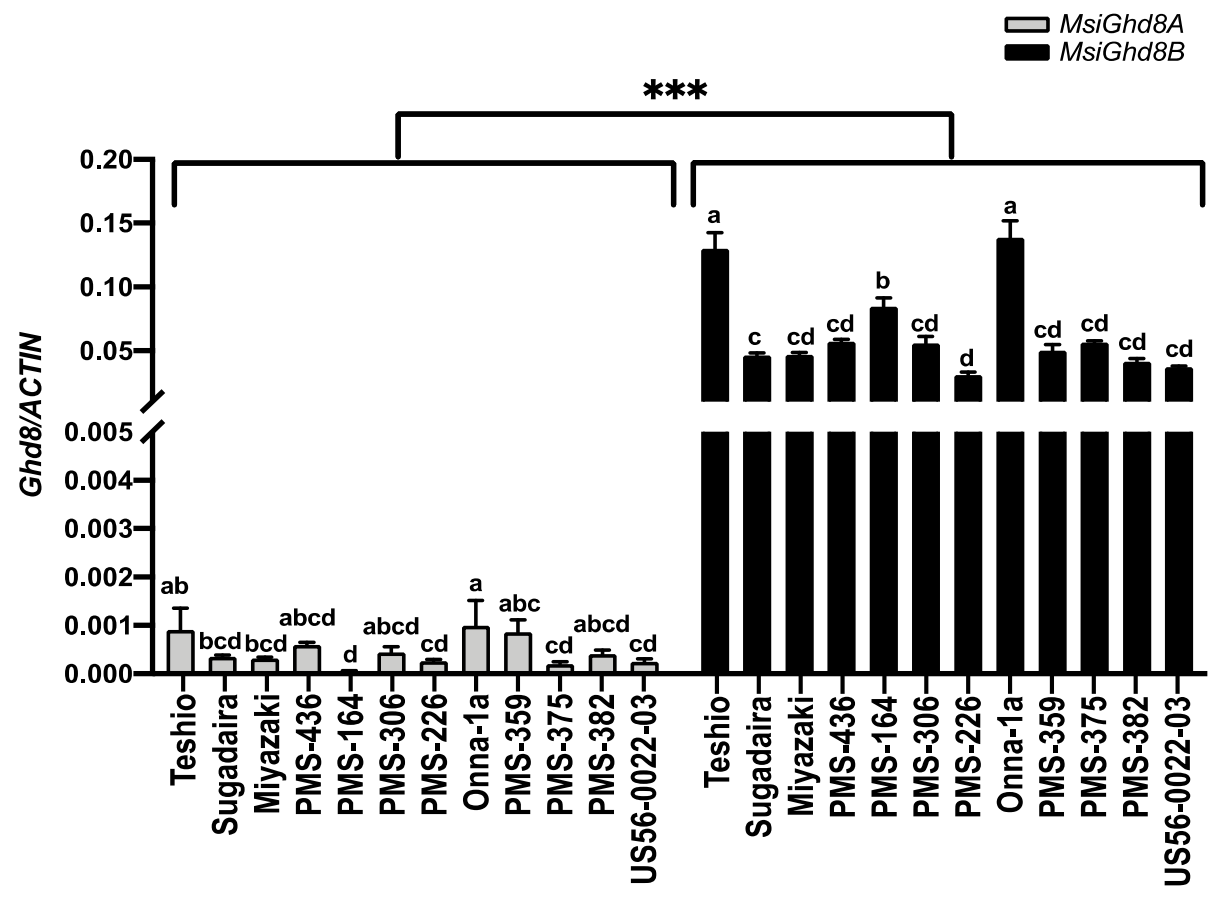

Figure 4. Expression of MsiGhd8 at Zeitgeber time 9 for 12 Miscanthus sinensis accessions under long days (15 h). Grey and black represent MsiGhd8A and MsiGhd8B, respectively. Relative mRNA levels are expressed as the ratios to ACTIN transcript levels. Mean $\pm 1 S E$ for three replications are given for each data point. A different letter on top of a bar indicates significant difference between accessions within each subgenome according to the Tukey HSD (95\% family-wise confidence level) multiple comparison tests. ${ }^{* * *}$ shown between the two subgenomes indicates a significant difference at $p<0.001$ according to the Student's $t$-test.

(a) MsiGhd8A
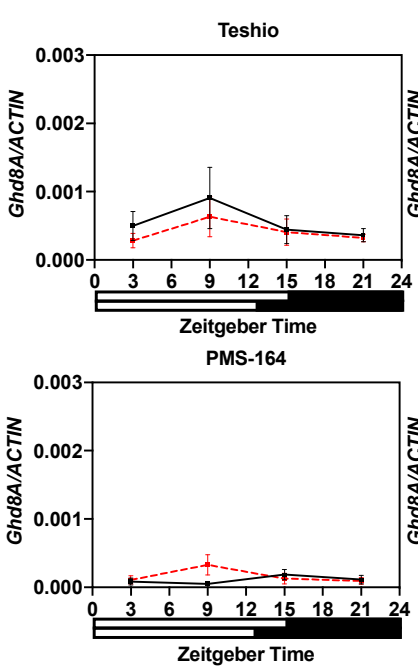

PMS-359

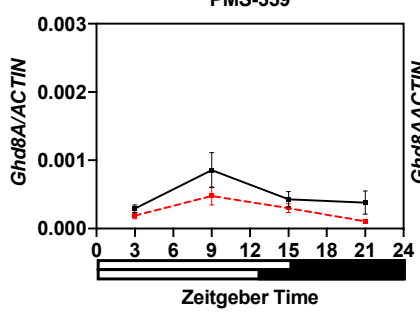

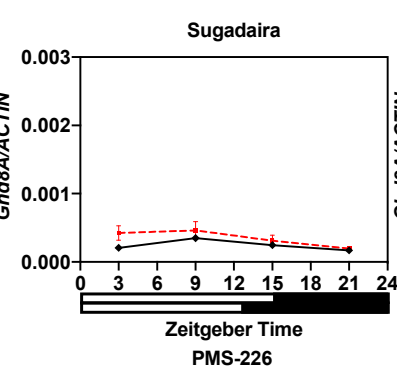

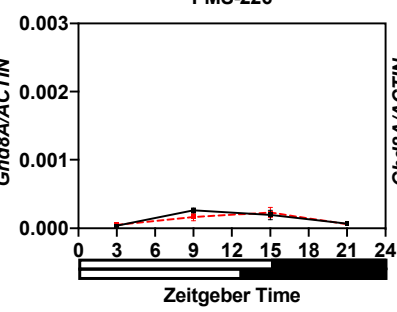

PMS-375

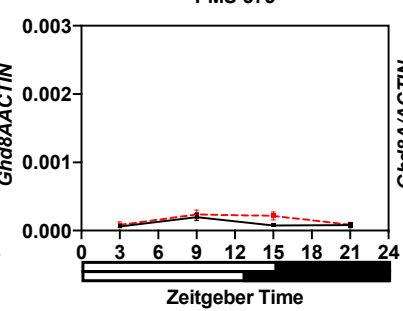

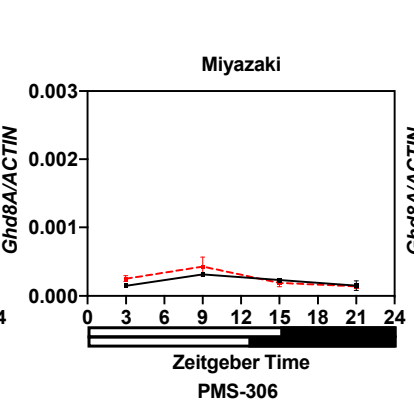
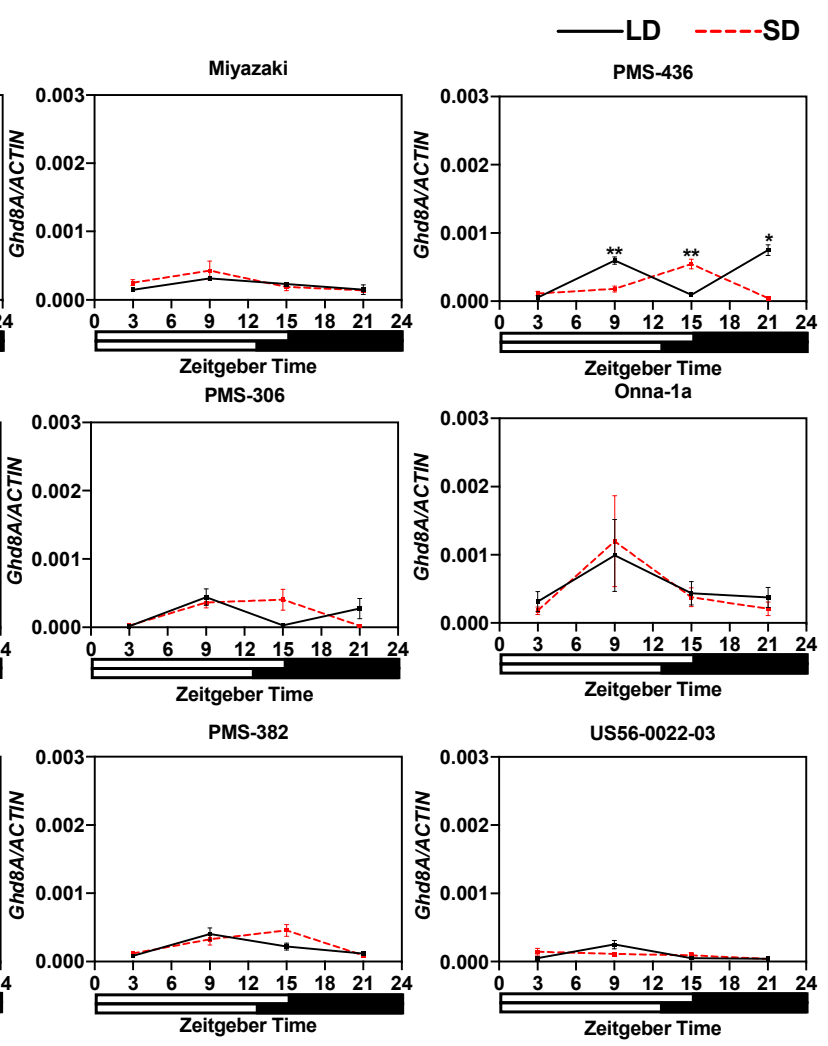

Figure 5. Cont. 
(b) MsiGhd8B
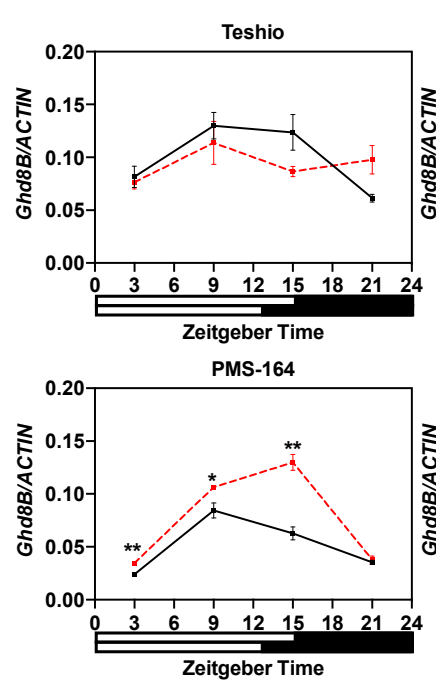

PMS-359

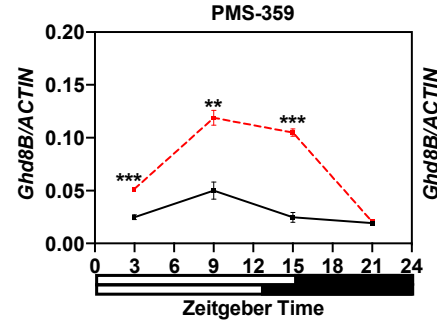

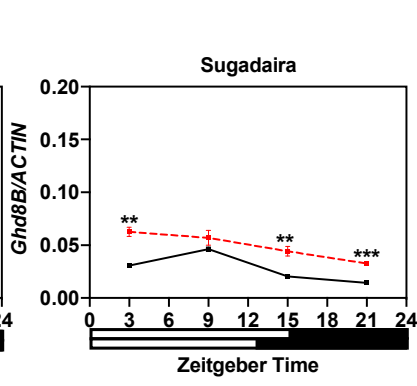

PMS-306

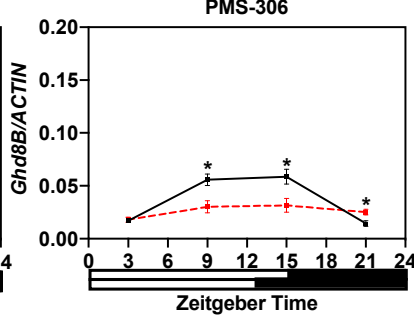

PMS-375

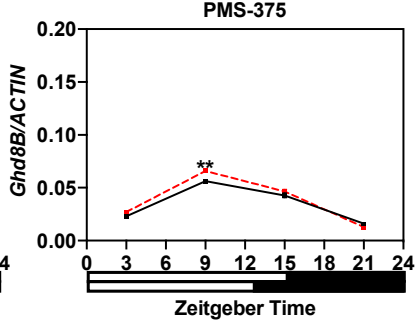

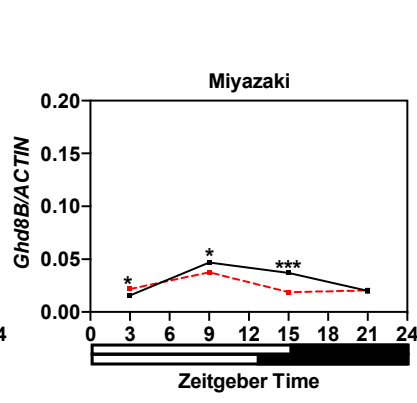

PMS-226

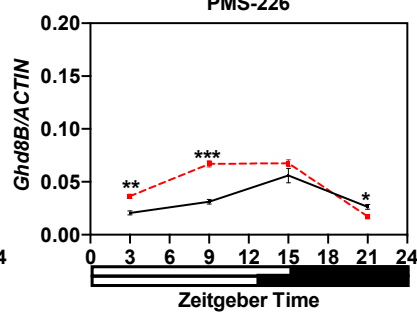

PMS-382

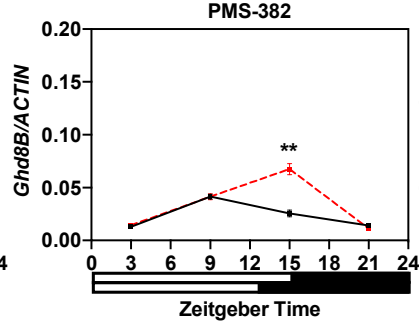

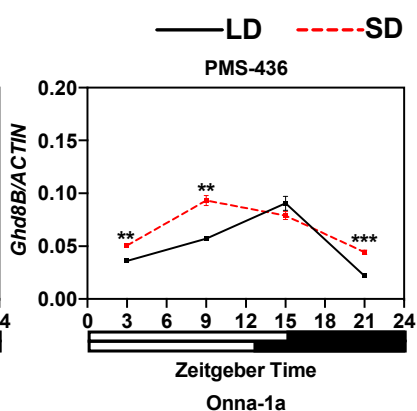

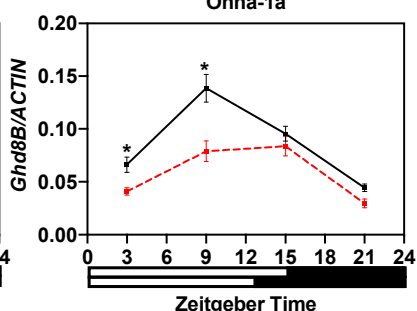

US56-0022-03

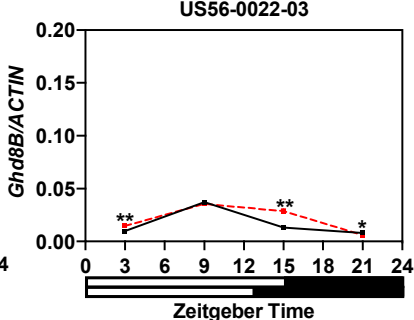

Figure 5. Diurnal expression of MsiGhd8 in 12 Miscanthus sinensis genotypes under long days (15 h, long-day (LD); solid black lines) and short days (12.5 h, short-day (SD); red dashed line). (a) MsiGhd8A and (b) MsiGhd8B. Relative mRNA levels are expressed as the ratios to ACTIN transcript levels. The numbers below the x-axis indicate Zeitgeber times (ZT) of the day. The white bar at the bottom of each graph indicates the light period and the black bar indicates the dark period. Mean \pm 1SE for three replications are given for each data point. Asterisks indicate significant difference between the two means under LD and SD at the same ZT of the day (Student's $t$-test, ${ }^{*} p<0.05,{ }^{* *} p<0.01,{ }^{* * *} p<0.001$ ). No asterisk indicates the difference between the two means is not statistically significant $(p<0.05)$.

\section{Discussion}

The results of the current study demonstrate that Ghd8 is present in M. sinensis, and likely contributes to a regulatory function for flowering time in this species in a manner that is similar to that in rice. Firstly, collinearity analysis revealed that two homoeologous Ghd8 loci (Misin13G040800 and Misin07G127500), one each in the two M. sinensis subgenomes (MsA and MsB), corresponded to the same genomic region on rice Chr.08 (LOC_Os08g07740) and sorghum Chr.07 (Sobic.007g059500) (Figure S1 and Table S2), which was consistent with the known paleo-duplications (rice Chr.08- sorghum Chr.07, sorghum Chr.07- Miscanthus Chr.13 and Chr.07) from the ancestral grass chromosomal groups [29,40,41]. Additionally, at each of the two homoeologous Ghd8 loci in M. sinensis, each accession in this study had at least one putatively functional full-length allelic copy containing a highly conserved HAP3/NF-YB DNA-binding domain that is required for the transcription factor function of Ghd8 in rice [22] and A. thaliana [61]. Moreover, the two homoeologous Ghd8 loci in $M$. sinensis expressed and may have a conserved function to regulate flowering time. If the $M$. sinensis Ghd8 genes were non-functional, we would expect a high frequency of accessions to have no functional alleles due to a lack of selection pressure, but this was not observed. Moreover, the $M$. sinensis $G h d 8$ genes were highly expressed (especially from the B subgenome), which is a necessary requirement for function.

Perhaps the strongest evidence for Ghd8 having a role in regulating the photoperiodsensitive induction of flowering in $M$. sinensis comes from the observed differences in the gene's expression under LD relative to SD during the day and its relationship to observed 
days to first flower among the accessions. If the critical time for Ghd8 to suppress Ehd1 via Ghd7 is in the morning, as was reported for rice [34], or at ZT9 for M. sinensis, as evidenced by a frequent peak at that time, then an LD/SD Ghd8 expression ratio $>1$ would be expected to delay or prevent flowering under LD and hasten flowering under SD, whereas a LD/SD ratio $<1$ would be expected to do the opposite (i.e., hasten flowering under LD and delay or prevent flowering under SD). A value of one for the day LD/SD Ghd8 expression ratio would indicate that Ghd8 did not regulate flowering time in that accession, and that other genes conferred any observed differences in flowering time associated with day length. For the M. sinensis B subgenome, four of the eight accessions with ZT9 LD/SD Ghd8 expression ratios differing from $\sim 1$ had values that were consistent with their observed flowering times (Table 1, Figure 5). Two of these four accessions (Miyazaki and PMS-306) had ZT9 LD/SD MsiGhd8B expression ratios $>1$ and flowered substantially earlier under 12.5 than $15 \mathrm{~h}$ day length, similar to the short-day (SD) response reported for rice [22,23]. The other two accessions (PMS-436 and PMS-164) had ZT9 LD/SD MsiGhd8B expression ratios $<1$ and flowered early under $15 \mathrm{~h}$ but failed to flower under $12.5 \mathrm{~h}$ day lengths; at ZT 3, both accessions also had LD/SD MsiGhd8B expression ratios $<1$ and a third accession, Sugadaira, performed similarly with an LD/SD ratio $<1$ at ZT3 but not at ZT9. Notably, the five accessions with day LD/SD MsiGhd8B expression ratios that were consistent with their flowering times were among the six most northerly accessions $\left(\geq 29.9^{\circ} \mathrm{N}\right)$ in the panel (only Teshio was not included), suggesting that MsiGhd8B regulation of flowering time may predominate in $M$. sinensis from high latitudes. The three tropical accessions with Ghd8 expression ratios $\sim 1$ uniquely did not flower under $15 \mathrm{~h}$ but did flower under $12.5 \mathrm{~h}$ day length, suggesting that this adaptation was conferred not by Ghd8 but some other, yet to be determined gene(s). Given that grasses have multiple pathways to regulate flowering time, including two known major pathways for photoperiod regulation of flowering time that each has multiple modifiers, we would not expect every accession in the panel to have its flowering time predominantly conferred by any one gene, including Ghd8. Nevertheless, we identified a signal of $G h d 8$ regulation of flowering time from nearly half of the $M$. sinensis accessions in the panel.

In contrast to the B genome, two lines of evidence suggest that the M. sinensis $\mathrm{A}$ genome homoeolog of Ghd8 does not substantially contribute to the photoperiod regulation of flowering time. First, eleven of the twelve accessions in the panel had ZT9 LD/SD $M s i G h d 8 A$ expression ratios $\sim 1$, yet all the accessions studied had different flowering time responses to LD or SD. Second, the expression of MsiGhd8A was substantially lower than the expression of $M s i G h d 8 B$ for each accession. The lower expression observed for MsiGhd8A than MsiGhd8B was consistent with a previously observed M. sinensis genomewide expression bias in favor of the B subgenome, with $\sim 10 \%$ more pairs of genes having higher expression in the B subgenome [41]. Thus, MsiGhd8A may be a case of reduced or neo-functionalization, which is common in organisms with duplicated genomes [62].

The four nsSNVs identified in the HAP3/NF-YB domain of MsiGhd8 from five accessions (Table S1) could have an important effect on protein stability and function. Though the sample size is limited, it is worthwhile to consider what role these variants might have in regulating the flowering time of $M$. sinensis. If the $M$. sinensis $G h d 8$ functions similarly to the rice Ghd8, by regulating Ghd7 as part of a complex with HD1 and HAP5b [34], then there is the potential for reduced stability of the complex to affect the phenotype. Complex formation, such as Ghd8-OsHAP5b-Hd1, and DNA-binding are stochastic processes that can be affected by the concentration of the molecules involved. For example, if expressed copies of Ghd8 that have a non-functional or reduced-functioning DNA binding site produce protein molecules that remain able to form a complex with the products of HD1 and HAP5b, then they may compete with copies of Ghd8 that have fully functional DNA binding sites, thereby reducing the quantity of functional complex and consequently reducing the transcription of Ghd7 and promoting flowering. Similarly, copies of Ghd8 that have a conserved DNA binding site, but which can form a complex that has an unstable conformation, may not be able to promote Ghd7 transcription, yet may compete for Ghd7 
binding sites with molecules of the complex that can act as a functional transcription factor. In domesticated rice, non-functional alleles of $G h d 7$, Ghd8 and $H d 1$ enabled early flowering and thus the expansion of cultivation to high latitudes for food production [63], whereas for undomesticated $M$. sinensis, natural selection appears to have resulted in functional alleles Ghd8 and Hd1 [33], conferring adaptation to high latitudes. For M. sinensis Hd1, a high frequency of non-functional alleles differentiated accessions from the Japanese archipelago and with those from mainland Asia [33], which is different from what we observed for Ghd8 in the current study.

Further research is needed to quantify the effects of individual putative functional MsiGhd8 alleles with nsSNVs and/or sSNVs on flowering time in response to day length. These studies can evaluate segregating populations derived from controlled biparental crosses, or be achieved by gene editing. The current study provides information on which alleles are present in different accessions that can be used to conduct genetics studies of segregating biparental populations. Additionally, the sequence data obtained by the current study for many different natural MsiGhd8 alleles can be used to plan geneediting studies in Miscanthus, rice or other species to dissect function while controlling for genetic background.

Dong et al. [7] observed that short days $(<12.5 \mathrm{~h})$ were also a signal for $M$. sinensis from high latitude plants to induce a short-internode dormancy response, which is an adaptation to protect apical meristems from damaging low temperatures during winter in high latitudes, and this dormancy response was epistatic to flowering. Similar dormancy responses to short days have been found in several quantitative short-day, perennial, C4 grasses, including M. sacchariflorus [4], switchgrass (Panicum virgatum) [64] and big bluestem (Andropogon gerardii) [65]. Additional research is needed to determine whether MsiGhd8 also mediates dormancy directly or indirectly.

In Arabidopsis and rice, extensive studies have revealed the underlying genetic mechanisms for regulating heading date. Using yeast and animal systems, it has been demonstrated that HAPs, a CCAAT-box-binding transcription factor, form a heterotetramer or heterotrimer for transcription activation. In $A$. thaliana, $H A P 3 b$ subunits can directly interact with $H d 1 / C O$ through its CCT-domain, forming CCAAT-binding CBF complexes that bind to $F T$ promoters and activate transcription to promote flowering under LD [66,67]. In rice, the grass-specific gene Ghd7 is upregulated by a Ghd8-OsHAP5b-Hd1 complex under LD, enabling $G h d 7$ to suppress Ehd1 and delay flowering [36,63,68-72]. However, Hd1/CO also competes with the complexes to promote $H d 3 a / R F T 1$ expression, creating a tradeoff relationship for photoperiod sensitive flowering under SD conditions. Thus, the regulatory network controlling flowering time is complex and quantitative, which likely accounts for the great plasticity of this trait in diverse populations. Whether MsiGhd8 protein can bind these flowering-related gene products ( $\mathrm{Hd1} / \mathrm{CO}$ and Ghd7) forming NF-Y complexes as described in rice remains to be confirmed in future studies, but the results of the current study suggest it is likely.

In addition to flowering time, $G h d 8$ has been found to regulate multiple developmental and physiological processes in rice. In previous studies, OsGhd8 has been associated with stress tolerance and regulation of photosynthesis [23,73,74]. OsGhd8 up-regulated MONOCULM 1 (MOC1), a key gene controlling tillering and branching; this increased the number of tillers and primary and secondary branches [23]. Wang et al. [73] found a cisregulatory variation in the Ghd8 promoter, associated with cold tolerance, thus contributing significantly to the ecological adaptation of rice varieties to high latitudes. Adachi et al. [74] indicated that CARBON ASSIMILATION RATE 8 (CAR8), identical to DTH8/Ghd8/LHD1, affected multiple physiological aspects relating to photosynthesis in rice, such as $\mathrm{CO}_{2}$ assimilation rate and hydraulic conductivity. Given the great allelic diversity observed for M. sinenesis Ghd8 in the current study, it would be desirable to determine if this gene also regulates a range of important physiological and developmental traits of Miscanthus.

In summary, this study identified two homoeologous loci of MsiGhd8 among a mini-core collection of $M$. sinensis, with one on each of this paleo-allotetraploid species' 
subgenomes. Several alleles and predicted amino acid sequence variants of MsiGhd8 showed a geographic and latitudinal distribution. The gene expression of MsiGhd8 correlated with the flowering date for some accessions in response to the photoperiod. The diverse MsiGhd8 expression patterns illustrated the complicated flowering regulatory network in Miscanthus. Further studies will be necessary to clarify the molecular mechanism of regulatory networks of flowering-related genes in Miscanthus, and to potentially improve biomass yield and quality by the regulation of the reproductive phase.

Supplementary Materials: The following are available online at https:/ / www.mdpi.com/2073-442 5/12/2/288/s1. Figure S1: Chromosome organization of Ghd8 gene orthologous regions (100 kbp) from Oryza sativa, Sorghum bicolor and Miscanthus sinensis. Figure S2: Geographical distribution of MsiGhd8A and MsiGhd8B alleles in Miscanthus sinensis. Table S1: A summary of polymorphic sites in MsiGhd8 open reading frames (ORFs) from 12 Miscanthus sinensis accessions. Table S2: Colinear genes near orthologs of Ghd8 in Miscanthus sinensis, Sorghum bicolor, and Oryza sativa.

Author Contributions: Conceptualization, T.Y. and E.J.S.; methodology, M.X. and H.N.; formal analysis, Z.G.; investigation, Z.G.; resources, T.Y., E.J.S. and L.V.C.; data curation, Z.G. and M.X.; writing-original draft preparation, Z.G.; writing—review and editing, Z.G., M.X., T.Y. and E.J.S.; supervision, T.Y. and E.J.S.; funding acquisition, T.Y. and E.J.S. All authors have read and agreed to the published version of the manuscript.

Funding: This research was supported by the DOE Office of Science, Office of Biological and Environmental Research (BER), grant nos. DE-SC0012379 and DE-SC0016264, and DE-SC0018420 (Center for Advanced Bioenergy and Bioproducts Innovation). This work was partially supported by Grants-in-Aid for Scientific Research (No. 17H04615 to T.Y.) from the Japanese Ministry of Education, Science, Sports and Culture. E.J.S. gratefully acknowledges support from Hokkaido University's visiting professor program. Z.G. gratefully acknowledges the China Scholarship Council to pursue her doctoral research at the Hokkaido University, Japan.

Institutional Review Board Statement: Not applicable.

Informed Consent Statement: Not applicable.

Data Availability Statement: All data necessary for confirming the conclusions of the article are present within the article, Figures and Tables, and within Supplementary Tables and Figures.

Acknowledgments: We thank Yoichiro Hoshino for providing greenhouse space in Hokkaido University and Sarah J Lipps for preparing divisions of the Miscanthus entries at the University of Illinois, Urbana-Champaign, Urbana, IL.

Conflicts of Interest: The authors declare no conflict of interest.

\section{References}

1. Hodkinson, T.R.; Klaas, M.; Jones, M.B.; Prickett, R.; Barth, S. Miscanthus: A case study for the utilization of natural genetic variation. Plant Genet. Resour. Charact. Util. 2015, 13, 219-237. [CrossRef]

2. Greef, J.; Deuter, M. Syntaxonomy of Miscanthus $\times$ giganteus GREEF et DEU. Angew. Bot. 1993, 67, 87-90.

3. Heaton, E.A.; Dohleman, F.G.; Long, S.P. Meeting US biofuel goals with less land: The potential of Miscanthus. Glob. Chang. Biol. 2008, 14, 2000-2014. [CrossRef]

4. Jensen, E.; Robson, P.; Norris, J.; Cookson, A.; Farrar, K.; Donnison, I.; Clifton-Brown, J. Flowering induction in the bioenergy grass Miscanthus sacchariflorus is a quantitative short-day response, whilst delayed flowering under long days increases biomass accumulation. J. Exp. Bot. 2013, 64, 541-552. [CrossRef]

5. Robson, P.; Jensen, E.; Hawkins, S.; White, S.R.; Kenobi, K.; Clifton-Brown, J.; Donnison, I.; Farrar, K. Accelerating the domestication of a bioenergy crop: Identifying and modelling morphological targets for sustainable yield increase in Miscanthus. J. Exp. Bot. 2013, 64, 4143-4155. [CrossRef] [PubMed]

6. Iqbal, Y.; Kiesel, A.; Wagner, M.; Nunn, C.; Kalinina, O.; Hastings, A.F.S.J.; Clifton-Brown, J.C.; Lewandowski, I. Harvest time optimization for combustion quality of different Miscanthus genotypes across Europe. Front. Plant Sci. 2017, 8, 727. [CrossRef] [PubMed]

7. Dong, H.; Clark, L.V.; Jin, X.; Anzoua, K.; Bagmet, L.; Chebukin, P.; Dzyubenko, E.; Dzyubenko, N.; Ghimire, B.K.; Heo, K.; et al. Managing flowering time in Miscanthus and sugarcane to facilitate intra- and intergeneric crosses. PLoS ONE 2021, 16, e0240390. [CrossRef] 
8. Jensen, E.; Farrar, K.; Thomas-Jones, S.; Hastings, A.; Donnison, I.; Clifton-Brown, J. Characterization of flowering time diversity in Miscanthus species. GCB Bioenergy 2011, 3, 387-400. [CrossRef]

9. Hastings, A.; Mos, M.; Yesufu, J.A.; McCalmont, J.; Schwarz, K.; Shafei, R.; Ashman, C.; Nunn, C.; Schuele, H.; Cosentino, S.; et al. Economic and environmental assessment of seed and rhizome propagated Miscanthus in the UK. Front. Plant Sci. 2017, 8, 1058. [CrossRef]

10. Clifton-Brown, J.; Harfouche, A.; Casler, M.D.; Dylan Jones, H.; Macalpine, W.J.; Murphy-Bokern, D.; Smart, L.B.; Adler, A.; Ashman, C.; Awty-Carroll, D.; et al. Breeding progress and preparedness for mass-scale deployment of perennial lignocellulosic biomass crops switchgrass, Miscanthus, willow and poplar. GCB Bioenergy 2019, 11, 118-151. [CrossRef] [PubMed]

11. Deuter, M. Breeding approaches to improvement of yield and quality in Miscanthus grown in Europe. In European Miscanthus Improvement (FAIR3 CT-96-1392) Final Report; Lewandowski, I., Clifton-Brown, J., Eds.; Institute of Crop Production and Grassland Research, University of Hohenheim: Stuttgart, Germany, 2000; pp. 28-52.

12. Song, Y.H.; Shim, J.S.; Kinmonth-Schultz, H.A.; Imaizumi, T. Photoperiodic flowering: Time measurement mechanisms in leaves. Annu. Rev. Plant Biol. 2015, 66, 441-464. [CrossRef]

13. Yang, S.; Weers, B.D.; Morishige, D.T.; Mullet, J.E. CONSTANS is a photoperiod regulated activator of flowering in sorghum. BMC Plant Biol. 2014, 14, 1-15. [CrossRef] [PubMed]

14. Goretti, D.; Martignago, D.; Landini, M.; Brambilla, V.; Gómez-Ariza, J.; Gnesutta, N.; Galbiati, F.; Collani, S.; Takagi, H.; Terauchi, R.; et al. Transcriptional and post-transcriptional mechanisms limit Heading Date 1 (Hd1) function to adapt rice to high latitudes. PLoS Genet. 2017, 13, e1006530. [CrossRef] [PubMed]

15. Hayama, R.; Yokoi, S.; Tamaki, S.; Yano, M.; Shimamoto, K. Adaptation of photoperiodic control pathways produces short-day flowering in rice. Nature 2003, 422, 719-722. [CrossRef]

16. Izawa, T.; Mihara, M.; Suzuki, Y.; Gupta, M.; Itoh, H.; Nagano, A.J.; Motoyam, R.; Sawad, Y.; Yano, M.; Hirai, M.Y.; et al. Os-GIGANTEA confers robust diurnal rhythms on the global transcriptome of rice in the field. Plant Cell 2011, 23, 1741-1755. [CrossRef] [PubMed]

17. Doi, K.; Izawa, T.; Fuse, T.; Yamanouchi, U.; Kubo, T.; Shimatani, Z.; Yano, M.; Yoshimura, A. Ehd1, a B-type response regulator in rice, confers short-day promotion of flowering and controls FT-like gene expression independently of Hd1. Genes Dev. 2004, 18, 926-936. [CrossRef]

18. Murphy, R.L.; Morishige, D.T.; Brady, J.A.; Rooney, W.L.; Yang, S.; Klein, P.E.; Mullet, J.E. Ghd7 (Ma6) represses sorghum flowering in long days: Ghd7 alleles enhance biomass accumulation and grain production. Plant Genome 2014, 7, 1-10. [CrossRef]

19. Xue, W.; Xing, Y.; Weng, X.; Zhao, Y.; Tang, W.; Wang, L.; Zhou, H.; Yu, S.; Xu, C.; Li, X.; et al. Natural variation in Ghd7 is an important regulator of heading date and yield potential in rice. Nat. Genet. 2008, 40, 761-767. [CrossRef]

20. Yang, Q.; Li, Z.; Li, W.; Ku, L.; Wang, C.; Ye, J.; Li, K.; Yang, N.; Li, Y.; Zhong, T.; et al. CACTA-like transposable element in ZmCCT attenuated photoperiod sensitivity and accelerated the postdomestication spread of maize. Proc. Natl. Acad. Sci. USA 2013, 110, 16969-16974. [CrossRef]

21. Itoh, H.; Nonoue, Y.; Yano, M.; Izawa, T. A pair of floral regulators sets critical day length for Hd3a florigen expression in rice. Nat. Genet. 2010, 42, 635-638. [CrossRef]

22. Wei, X.; Xu, J.; Guo, H.; Jiang, L.; Chen, S.; Yu, C.; Zhou, Z.; Hu, P.; Zhai, H.; Wan, J. DTH8 suppresses flowering in rice, influencing plant height and yield potential simultaneously. Plant Physiol. 2010,153, 1747-1758. [CrossRef]

23. Yan, W.; Wang, P.; Chen, H.; Zhou, H.; Li, Q.; Wang, C.; Ding, Z.; Zhang, Y.; Yu, S.; Xing, Y.; et al. A major QTL, Ghd8, plays pleiotropic roles in regulating grain productivity, plant height, and heading date in rice. Mol. Plant 2011, 4, 319-330. [CrossRef]

24. Gómez-Ariza, J.; Galbiati, F.; Goretti, D.; Brambilla, V.; Shrestha, R.; Pappolla, A.; Courtois, B.; Fornara, F. Loss of floral repressor function adapts rice to higher latitudes in Europe. J. Exp. Bot. 2015, 66, 2027-2039. [CrossRef] [PubMed]

25. Gao, H.; Jin, M.; Zheng, X.; Chen, J.; Yuan, D.; Xin, Y.; Wang, M.; Huang, D.; Zhang, Z.; Zhou, K.; et al. Days to heading 7, a major quantitative locus determining photoperiod sensitivity and regional adaptation in rice. Proc. Natl. Acad. Sci. USA 2014, 111, 16337-16342. [CrossRef] [PubMed]

26. Yang, S.; Murphy, R.L.; Morishige, D.T.; Klein, P.E.; Rooney, W.L.; Mullet, J.E. Sorghum Phytochrome B inhibits flowering in long days by activating expression of SbPRR37 and SbGHD7, repressors of SbEHD1, SbCN8 and SbCN12. PLoS ONE 2014, 9, e105352. [CrossRef] [PubMed]

27. Murphy, R.L.; Klein, R.R.; Morishige, D.T.; Brady, J.A.; Rooney, W.L.; Miller, F.R.; Dugas, D.V.; Klein, P.E.; Mullet, J.E. Coincident light and clock regulation of pseudoresponse regulator protein 37 (PRR37) controls photoperiodic flowering in sorghum. Proc. Natl. Acad. Sci. USA 2011, 108, 16469-16474. [CrossRef] [PubMed]

28. Casto, A.L.; Mattison, A.J.; Olson, S.N.; Thakran, M.; Rooney, W.L.; Mullet, J.E. Maturity2, a novel regulator of flowering time in Sorghum bicolor, increases expression of SbPRR37 and SbCO in long days delaying flowering. PLoS ONE 2019, 14, e0212154. [CrossRef] [PubMed]

29. Dong, H.; Liu, S.; Clark, L.V.; Sharma, S.; Gifford, J.M.; Juvik, J.A.; Lipka, A.E.; Sacks, E.J. Genetic mapping of biomass yield in three interconnected Miscanthus populations. GCB Bioenergy 2018, 10, 165-185. [CrossRef]

30. Gifford, J.M.; Chae, W.B.; Swaminathan, K.; Moose, S.P.; Juvik, J.A. Mapping the genome of Miscanthus sinensis for QTL associated with biomass productivity. GCB Bioenergy 2015, 7, 797-810. [CrossRef] 
31. Jensen, E.; Shafiei, R.; Ma, X.; Serba, D.D.; Smith, D.P.; Slavov, G.T.; Robson, P.; Farrar, K.; Thomas Jones, S.; Swaller, T.; et al. Linkage mapping evidence for a syntenic QTL associated with flowering time in perennial C4 rhizomatous grasses Miscanthus and switchgrass. GCB Bioenergy 2021, 13, 98-111. [CrossRef]

32. Chalfun-Junior, A.; Franken, J.; Mes, J.J.; Marsch-Martinez, N.; Pereira, A.; Angenent, G.C. ASYMMETRIC LEAVES2-LIKE1 gene, a member of the AS2/LOB family, controls proximal-distal patterning in Arabidopsis petals. Plant Mol. Biol. 2005, 57, 559-575. [CrossRef]

33. Nagano, H.; Clark, L.V.; Zhao, H.; Peng, J.; Yoo, J.H.; Heo, K.; Yu, C.Y.; Anzoua, K.G.; Matsuo, T.; Sacks, E.J.; et al. Contrasting allelic distribution of $\mathrm{CO} / \mathrm{Hd} 1$ homologues in Miscanthus sinensis from the East Asian mainland and the Japanese archipelago. J. Exp. Bot. 2015, 66, 4227-4237. [CrossRef] [PubMed]

34. Wang, P.; Gong, R.; Yang, Y.; Yu, S. Ghd8 controls rice photoperiod sensitivity by forming a complex that interacts with Ghd7. BMC Plant Biol. 2019, 19, 1-14. [CrossRef]

35. Cai, X.; Ballif, J.; Endo, S.; Davis, E.; Liang, M.; Chen, D.; Dewald, D.; Kreps, J.; Zhu, T.; Wu, Y. A putative CCAAT-binding transcription factor is a regulator of flowering timing in Arabidopsis. Plant Physiol. 2007, 145, 98-105. [CrossRef]

36. Li, X.; Liu, H.; Wang, M.; Liu, H.; Tian, X.; Zhou, W.; Lü, T.; Wang, Z.; Chu, C.; Fang, J.; et al. Combinations of Hd2 and Hd4 genes determine rice adaptability to Heilongjiang Province, northern limit of China. J. Integr. Plant Biol. 2015, 57, 698-707. [CrossRef] [PubMed]

37. Fujino, K.; Yamanouchi, U.; Yano, M. Roles of the Hd5 gene controlling heading date for adaptation to the northern limits of rice cultivation. Theor. Appl. Genet. 2013, 126, 611-618. [CrossRef]

38. Gale, M.D.; Devos, K.M. Comparative genetics in the grasses. Proc. Natl. Acad. Sci. USA 1998, 95, 1971-1974. [CrossRef]

39. Glémin, S.; Bataillon, T. A comparative view of the evolution of grasses under domestication: Tansley review. New Phytol. 2009, 183, 273-290. [CrossRef] [PubMed]

40. Salse, J.; Abrouk, M.; Bolot, S.; Guilhot, N.; Courcelle, E.; Faraut, T.; Waugh, R.; Close, T.J.; Messing, J.; Feuillet, C. Reconstruction of monocotelydoneous proto-chromosomes reveals faster evolution in plants than in animals. Proc. Natl. Acad. Sci. USA 2009, 106, 14908-14913. [CrossRef] [PubMed]

41. Mitros, T.; Session, A.M.; James, B.T.; Wu, G.A.; Belaffif, M.B.; Clark, L.V.; Shu, S.; Dong, H.; Barling, A.; Holmes, J.R.; et al. Genome biology of the paleotetraploid perennial biomass crop Miscanthus. Nat. Commun. 2020, 11, 1-11. [CrossRef]

42. Kim, C.; Zhang, D.; Auckland, S.A.; Rainville, L.K.; Jakob, K.; Kronmiller, B.; Sacks, E.J.; Deuter, M.; Paterson, A.H. SSR-based genetic maps of Miscanthus sinensis and M. sacchariflorus, and their comparison to sorghum. Theor. Appl. Genet. 2012, 124, 1325-1338. [CrossRef] [PubMed]

43. Swaminathan, K.; Chae, W.B.; Mitros, T.; Varala, K.; Xie, L.; Barling, A.; Glowacka, K.; Hall, M.; Jezowski, S.; Ming, R.; et al. A framework genetic map for Miscanthus sinensis from RNAseq-based markers shows recent tetraploidy. BMC Genomics 2012, 13, 142. [CrossRef] [PubMed]

44. Yang, L.; Liu, T.; Li, B.; Sui, Y.; Chen, J.; Shi, J.; Wing, R.A.; Chen, M. Comparative sequence analysis of the Ghd7 orthologous regions revealed movement of Ghd7 in the grass genomes. PLoS ONE 2012, 7, e50236. [CrossRef]

45. Ming, R.; Del Monte, T.A.; Hernandez, E.; Moore, P.H.; Irvine, J.E.; Paterson, A.H. Comparative analysis of QTLs affecting plant height and flowering among closely-related diploid and polyploid genomes. Genome 2002, 45, 794-803. [CrossRef] [PubMed]

46. Hu, F.; Tao, D.; Sacks, E.; Fu, B.; Xu, P.; Li, J.; Yang, Y.; McNally, K.; Khush, G.S.; Paterson, A.H.; et al. Convergent evolution of perenniality in rice and sorghum. Proc. Natl. Acad. Sci. USA 2003, 100, 4050-4054. [CrossRef] [PubMed]

47. Van der Weijde, T.; Kamei, C.L.A.; Severing, E.I.; Torres, A.F.; Gomez, L.D.; Dolstra, O.; Maliepaard, C.A.; McQueen-Mason, S.J.; Visser, R.G.F.; Trindade, L.M. Genetic complexity of Miscanthus cell wall composition and biomass quality for biofuels. BMC Genomics 2017, 18, 406. [CrossRef]

48. Liu, H.; Liu, H.; Zhou, L.; Zhang, Z.; Zhang, X.; Wang, M.; Li, H.; Lin, Z. Parallel domestication of the heading date 1 gene in cereals. Mol. Biol. Evol. 2015, 32, 2726-2737. [CrossRef] [PubMed]

49. Clark, L.V.; Brummer, J.E.; Głowacka, K.; Hall, M.C.; Heo, K.; Peng, J.; Yamada, T.; Yoo, J.H.; Yu, C.Y.; Zhao, H.; et al. A footprint of past climate change on the diversity and population structure of Miscanthus sinensis. Ann. Bot. 2014, 114, 97-107. [CrossRef]

50. Clark, L.V.; Stewart, J.R.; Nishiwaki, A.; Toma, Y.; Kjeldsen, J.B.; Jørgensen, U.; Zhao, H.; Peng, J.; Yoo, J.H.; Heo, K.; et al. Genetic structure of Miscanthus sinensis and Miscanthus sacchariflorus in Japan indicates a gradient of bidirectional but asymmetric introgression. J. Exp. Bot. 2015, 66, 4213-4225. [CrossRef]

51. Doyle, J.J.; Doyle, J.L. Isolation of plant DNA from fresh tissue. Focus 1990, 12, 13-15.

52. Dwiyanti, M.S.; Yamada, T.; Sato, M.; Abe, J.; Kitamura, K. Genetic variation of $\gamma$-tocopherol methyltransferase gene contributes to elevated $\alpha$-tocopherol content in soybean seeds. BMC Plant Biol. 2011, 11, 152. [CrossRef] [PubMed]

53. Bookout, A.L.; Mangelsdorf, D.J. Quantitative real-time PCR protocol for analysis of nuclear receptor signaling pathways. Nucl. Recept. Signal. 2003, 1, nrs.01012. [CrossRef] [PubMed]

54. Kumar, S.; Stecher, G.; Li, M.; Knyaz, C.; Tamura, K. MEGA X: Molecular evolutionary genetics analysis across computing platforms. Mol. Biol. Evol. 2018, 35, 1547-1549. [CrossRef] [PubMed]

55. Stecher, G.; Tamura, K.; Kumar, S. Molecular evolutionary genetics analysis (MEGA) for macOS. Mol. Biol. Evol. 2020, 37, 1237-1239. [CrossRef]

56. Zuckerkandl, E.; Pauling, L. Evolutionary divergence and convergence in proteins. In Evolving Genes and Proteins; Vernon, B., Vogel, H.J., Eds.; Academic Press: New York, NY, USA, 1965; pp. 97-166. ISBN 9781483227344. 
57. Thompson, J.D.; Higgins, D.G.; Gibson, T.J. CLUSTAL W: Improving the sensitivity of progressive multiple sequence alignment through sequence weighting, position-specific gap penalties and weight matrix choice. Nucleic Acids Res. 1994, 22, 4673-4680. [CrossRef] [PubMed]

58. Saitou, N.; Nei, M. The neighbor-joining method: A new method for reconstructing phylogenetic trees. Mol. Biol. Evol. 1987, 4, 406-425. [CrossRef]

59. Kimura, M. A simple method for estimating evolutionary rates of base substitutions through comparative studies of nucleotide sequences. J. Mol. Evol. 1980, 16, 111-120. [CrossRef]

60. Felsenstein, J. Confidence limits on phylogenies: An approach using the bootstrap. Evolution 1985, 39, 783-791. [CrossRef]

61. Kumimoto, R.W.; Adam, L.; Hymus, G.J.; Repetti, P.P.; Reuber, T.L.; Marion, C.M.; Hempel, F.D.; Ratcliffe, O.J. The Nuclear Factor Y subunits NF-YB2 and NF-YB3 play additive roles in the promotion of flowering by inductive long-day photoperiods in Arabidopsis. Planta 2008, 228, 709-723. [CrossRef] [PubMed]

62. Lallemand, T.; Leduc, M.; Landès, C.; Rizzon, C.; Lerat, E. An overview of duplicated gene detection methods: Why the duplication mechanism has to be accounted for in their choice. Genes 2020, 11, 1046. [CrossRef] [PubMed]

63. Zhang, J.; Zhou, X.; Yan, W.; Zhang, Z.; Lu, L.; Han, Z.; Zhao, H.; Liu, H.; Song, P.; Hu, Y.; et al. Combinations of the Ghd7, Ghd8 and Hd1 genes largely define the ecogeographical adaptation and yield potential of cultivated rice. New Phytol. 2015, 208, 1056-1066. [CrossRef] [PubMed]

64. Castro, J.C.; Boe, A.; Lee, D.K. A simple system for promoting flowering of upland switchgrass in the greenhouse. Crop Sci. 2011, 51, 2607-2614. [CrossRef]

65. McMillan, C. The role of ecotypic variation in the distribution of the central grassland of North America. Ecol. Monogr. 1959, 29, 285-308. [CrossRef]

66. Wenkel, S.; Turck, F.; Singer, K.; Gissot, L.; Le Gourrierec, J.; Samach, A.; Coupland, G. CONSTANS and the CCAAT box binding complex share a functionally important domain and interact to regulate flowering of Arabidopsis. Plant Cell 2006, 18, 2971-2984. [CrossRef]

67. Ben-Naim, O.; Eshed, R.; Parnis, A.; Teper-Bamnolker, P.; Shalit, A.; Coupland, G.; Samach, A.; Lifschitz, E. The CCAAT binding factor can mediate interactions between CONSTANS-like proteins and DNA. Plant J. 2006, 46, 462-476. [CrossRef] [PubMed]

68. Zong, W.; Ren, D.; Huang, M.; Sun, K.; Feng, J.; Zhao, J.; Xiao, D.; Xie, W.; Liu, S.; Zhang, H.; et al. Strong photoperiod sensitivity is controlled by cooperation and competition among Hd1, Ghd7 and DTH8 in rice heading. New Phytol. 2021, 229, 1635-1649. [CrossRef] [PubMed]

69. Du, A.; Tian, W.; Wei, M.; Yan, W.; He, H.; Zhou, D.; Huang, X.; Li, S.; Ouyang, X. The DTH8-Hd1 module mediates day-lengthdependent regulation of rice flowering. Mol. Plant 2017, 10, 948-961. [CrossRef]

70. Zhang, B.; Liu, H.; Qi, F.; Zhang, Z.; Li, Q.; Han, Z.; Xing, Y. Genetic interactions among Ghd7, Ghd8, OsPRR37 and Hd1 contribute to large variation in heading date in rice. Rice 2019, 12, 48. [CrossRef]

71. Liu, J.; Gong, J.; Wei, X.; Yang, S.; Huang, X.; Li, C.; Zhou, X. Dominance complementation of Hd1 and Ghd8 contributes to extremely late flowering in two rice hybrids. Mol. Breed. 2020, 40, 1-10. [CrossRef]

72. Nemoto, Y.; Nonoue, Y.; Yano, M.; Izawa, T. Hd1, a CONSTANS ortholog in rice, functions as an Ehd1 repressor through interaction with monocot-specific CCT-domain protein Ghd7. Plant J. 2016, 86, 221-233. [CrossRef]

73. Wang, P.; Xiong, Y.; Gong, R.; Yang, Y.; Fan, K.; Yu, S. A key variant in the cis-regulatory element of flowering gene Ghd8 associated with cold tolerance in rice. Sci. Rep. 2019, 9, 1-14. [CrossRef] [PubMed]

74. Adachi, S.; Yoshikawa, K.; Yamanouchi, U.; Tanabata, T.; Sun, J.; Ookawa, T.; Yamamoto, T.; Sage, R.F.; Hirasawa, T.; Yonemaru, J. Fine mapping of Carbon assimilation rate 8 , a quantitative trait locus for flag leaf nitrogen content, stomatal conductance and photosynthesis in rice. Front. Plant Sci. 2017, 8, 60. [CrossRef] [PubMed] 